WSRC-TR-2004-00040

\title{
Microstructural Examination and Deuterium Permeation Testing of Advanced Coatings for Tritium Service
}

\author{
P.S. Korinko
}

January 2004

Westinghouse Savannah River Company

Aiken, SC 29808

Prepared for the U.S. Department of Energy under Contract DE-AC09-96SR18500 
SMTD

STRATEGIC MATERIALS TECHNOLOGY DEPARTMENT

$\begin{array}{ll}\text { Keywords: } & \text { Stainless Steel } \\ & \text { Permeation } \\ & \text { Tritium Service }\end{array}$

Retention: Permanent

\title{
Microstructural Examination and Deuterium Permeation Testing of Advanced Coatings for Tritium Service
}

\author{
P.S. Korinko \\ Materials Compatibility and Welding Technology Group \\ ISSUED: January 2004
}

SRTC SAVANNAH RIVER TECHNOLOGY CENTER, AIKEN, SC 29808

Westinghouse Savannah River Company

Prepared for the U.S. Department of Energy under Contract DE-AC09-96SR18500 
Document: WSRC-TR-2004-00040

Title: $\quad$ Microstructural Examination and Deuterium Permeation Testing of Advanced Coatings for Tritium Service

APPROVALS

P.S. Korinko, Author

Date: $1-16-2004$

Materials Compatibility and Welding Technology Group

Materials Technology Section

E.A. Clark, Technical Reviewer

Date: $1-16-2004$

Materials Compatibility and Welding Technology Group

Materials Technology Section

S.L. West, Manager

Date: $1-20-2004$

Materials Compatibility and Welding Technology Group

Materials Technology Section

N.C. Iyer, Manager

Date: 1-23-2004

Materials Technology Section 
WSRC-TR-2004-00040

\section{Microstructural Examination and Deuterium Permeation Testing of Advanced Coatings for Tritium Service}

\section{TABLE OF CONTENTS}

Abstract ....

\section{LIST OF TABLES}

Table 1. Coating compositions and application methods 2

Table 2. Permeation tested samples conditions and raw data .................................................5

Table 3. Diffusivity and Permeability data extracted from raw data......................................... 6

\section{LIST OF FIGURES}

Fig. 1. Photographs of the permeation test facility. (a) overall (b) close-up of mass spectrometers, and (c) close-up of loaded sample 8

Fig. 2. Photomicrographs of (a) Simple aluminide at 100X (b) Simple aluminide at 500X (commonly used on getter beds and magnesium beds), (c) Plasma sprayed aluminum at 100X (d) Plasma sprayed aluminum at 500X (used for the TCON TCAP) (e) As sprayed HVOF NiCoCrAlY at 100X (f) As sprayed HVOF NiCoCrAlY at 500X (g) Heat treated HVOF NiCoCrAlY at 100X (h) heat treated HVOF NiCoCrAlY at 100X (i) Platinized HVOF NiCoCrAlY at $100 \mathrm{X}(\mathrm{j})$ Platinized HVOF at 500X (k) Platinum aluminized HVOF NiCoCrAlY at 100X (1) Platinum aluminized HVOF NiCoCrAlY at 500X (m) Aluminized HVOF NiCoCrAlY at 100X (n) Aluminized HVOF NiCoCrAlY at 500X (o) Platinum aluminide at $100 \mathrm{X}$ and (p) Platinum aluminide at 500X.

Fig. 3. Coating coupon from a magnesium bed container (a) overall view (b) metallographic cross-section showing two layer structure...... 13

Fig. 4. Simple aluminide coated 316 SS (a) SEM micrograph of overall coating (b) XEDA spectrum of outer region of coating (c) SEM micrograph showing interdiffusion zone (d) XEDA spectrum of dark spots in Fig. 4c. (e) XEDA spectrum of light gray areas in Fig. 4c......14-16 
WSRC-TR-2004-00040

Fig. 5. Plasma sprayed aluminum on 316 SS (a) SEM micrograph of coating and (b) typical

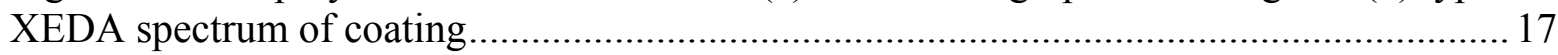

Fig. 6. As-sprayed HVOF NiCoCrAlY (a) SEM micrograph near interface (b) Typical XEDA spectrum (c) coating composition profile with base metal on left. 18-19

Fig.7. Heat treated HVOF NiCoCrAlY (a) SEM micrograph of coating (b) SEM micrograph near interface (c) typical XEDA spectrum from coating (XEDA spectrum from interface (e) coating composition profile with base metal on left. 20-22

Fig. 8. Platinized HVOF NiCoCrAlY (a) SEM Micrograph of overall coating (b) XEDA spectrum from outer layer of coating spot 4 (c) XEDA spectrum from Pt interdiffusion later spot 2 (d) XEDA spectrum from Pt interdiffusion later spot 1 (e) XEDA spectrum from unalloyed coating spot 5 . 23-25

Fig. 9. Platinum aluminized HVOF NiCoCrAlY (a) SEM micrograph (b) XEDA spectrum of outer coating spot 5 (c) XEDA spectrum of interdiffusion zone spot 4 (d) XEDA spectrum of unalloyed coating spot 2 . 26-27

Fig. 10. Aluminized HVOF NiCoCrAlY (a) SEM micrograph (b) XEDA spectrum from outer layer spot 3 (c) SEM micrograph of unaffected area (d) XEDA spectrum from unaffected area spot 4, dark gray (e) XEDA spectrum from unaffected area spot 5, light gray.... 28-30

Fig. 11. Platinum aluminide coated 316 SS (a) SEM micrograph (b) XEDA spectrum of Pt-rich phase (c) XEDA spectrum of matrix in Pt-rich zone (d) XEDA spectrum from the interdiffusion zone (e) XEDA spectrum from interdiffusion layer (f) XEDA spectrum from interdiffusion layer (g) coating composition profile with base metal on left. 31-34

Fig. 12. Variations used to improve the seal of the coated samples for testing. (a) schematic of sample loading using copper gaskets (b) schematic of machined gaskets (c) schematic of next generation sample for testing.... 35

Fig. 13 Typical pressure-time data obtained from (a) the bare sample and (b) the heat treated NiCoCrAlY coated sample.... 36 


\title{
Microstructural Examination and Deuterium Permeation Testing of Advanced Coatings for Tritium Service
}

\begin{abstract}
A plant directed research and development task to develop and study new, improved, and low cost tritium permeation barriers was initiated in FY02. The project was intended to determine the permeation rate and permeation reduction factor of substrate materials and coated materials. The samples were characterized for microstructural and microchemical consistency. Permeation tests were also run. The sample geometry and sample sealing method selected for the coatings posed significant schedule and technical challenges. Diffusivity data were consistent with published values but permeation data exhibited an unexpected sample to sample variation. The effort has lead to an improved sample design that will be used to support a Process Development task.
\end{abstract}

\section{Background}

Permeation reduction coatings are used in the SRS Tritium Facilities to reduce personnel exposure, to reduce tritium load on strippers, and to minimize losses. The permeation reduction coatings are primarily used on magnesium and uranium bed containers. The coating that has been used historically is aluminization of the stainless steel. This coating process uses a aluminum source and a thermal cycle to apply a diffused coating that consumes part of the base metal and forms an intermetallic, typically FeAl, surface layer. The coating application has resulted in cost and delivery issues recently. It is desirable to understand the mechanism for the permeation reduction and to find alternative lower cost coatings.

It is known that permeation of gases through materials is dependent on three material properties, the surface reactions, solubility and diffusivity (1). These three processes occur serially and if the rate of one step can be reduced then the overall permeability can be reduced. This project was undertaken to test advanced coatings and to characterize the baseline (uncoated) materials so that improvements in the understanding of the process of permeation could be achieved and to evaluate and develop new coatings. In addition, design data was to be generated for future facility applications.

Coatings that improve the permeation resistance of the system either have lower solubility, lower diffusivity or reduce the rate of surface related reactions. Materials such as aluminum, gold, and some refractory materials reportedly have low permeabilities due to low solubilities while some ceramic materials, aluminum oxide, titanium carbide, and other ceramic materials have low diffusivities and consequently low permeabilities. Intermetallic materials, such as iron aluminide, often have permeabilities nearing that of the ceramics. However, it is believed that the low permeation rate of this coating is controlled by the formation of aluminum oxide.

In this task, coatings were selected that would likely form an oxide layer on the coating. These coatings are well known in the aerospace industry for oxidation and sulphidation resistance. 
All of the permeation testing was to use a new permeation test facility. This facility was constructed using ADAPT funding. This PDRD task would be the first to utilize it. The facility was commissioned March 2003. Numerous logistic and administrative problems were overcome in order to initiate testing.

\section{Experimental}

A new permeation facility was designed and with assembly starting in FY02 and was completed in January 2003 with final commissioning being completed in March 2003. This facility is shown in Fig. 1. The sample geometry selected was a nominal 1.2 inch diameter disk of 0.020 inch thick 304 stainless steel. The samples were to be sealed between copper gaskets on knife edge seals similar to the method described in Ref. 2. In order to ensure samples for testing, a contract was let in FY02 to coat the disks with the materials and thicknesses listed in Table 1. These coatings were selected since they represent coatings and substrate materials in use in the plant, the coatings and substrate materials selected for the Tritium Facility Modernization and Consolidation Project (TCON), and advanced coatings. The coatings were applied by plating and diffusion processes, standard thermal spray processes, including plasma spray and high velocity oxy-fuel (HVOF) processes, and HVOF followed by diffusion processes.

Table 1. Coating compositions and application methods

\begin{tabular}{|l|l|l|l|}
\hline Coating & Composition & Typical Thickness (in) & Application Method \\
\hline Simple aluminide & $\mathrm{FeAl}$ & 0.003 & Diffusion \\
\hline Platinum aluminide & $(\mathrm{Pt}, \mathrm{Fe}) \mathrm{Al}$ & 0.003 & Diffusion \\
\hline Aluminum & $99 \% \mathrm{Al}$ & $0.010,0.020,0.030$ & Plasma spray \\
\hline NiCoCrAlY & $\begin{array}{l}\mathrm{Ni}, 17.5 \mathrm{Cr}, 22 \mathrm{Co}, \\
12.5 \mathrm{Al}, 0.6 \mathrm{Y}\end{array}$ & 0.010 & $\begin{array}{l}\text { High Velocity } \\
\text { Oxygen Fuel (HVOF) }\end{array}$ \\
\hline NiCoCrAlY + Pt & $\begin{array}{l}\text { same with Pt expected } \\
\text { to improve } \mathrm{Al}_{2} \mathrm{O}_{3} \\
\text { formation }\end{array}$ & $0.010+0.0005$ & HVOF + electroplate \\
\hline NiCoCrAlY + PtAl & $\begin{array}{l}\text { same with PtAl } \\
\text { expected to improve } \\
\mathrm{Al}_{2} \mathrm{O}_{3} \text { formation }\end{array}$ & $0.010+0.003$ & HVOF + Diffusion \\
\hline $\begin{array}{l}\text { NiCoCrAlY }+ \\
\text { Aluminide }\end{array}$ & $\begin{array}{l}\text { same with aluminide } \\
\text { expected to improve } \\
\mathrm{Al}_{2} \mathrm{O}_{3} \text { formation }\end{array}$ & $0.010+0.003$ & HVOF + Diffusion \\
\hline NiCoCrAlY + HT & $\begin{array}{l}\text { same except heat } \\
\text { treated to improve } \\
\text { uniformity and } \\
\text { adhesion }\end{array}$ & 0.010 & HVOF + heat treat \\
\hline
\end{tabular}

The microstructure of coated samples were characterized using optical microscopy and scanning electron microscopy (SEM). One sample of each type was sectioned and mounted. Polishing was accomplished using special techniques previously demonstrated for each specific coating. The samples were examined in the unetched condition for SEM and lightly etched for optical microscopy. 
Permeation testing was conducted in the new permeation test facility. Various disk samples were sealed between either flat copper gaskets, silver plated copper gaskets, or gold plated copper gaskets. If these failed to achieve an acceptable leak rate, the samples were sealed between copper gaskets that had been machined to reduce the surface contact on the sample.

Permeation testing was conducted by considering the permeation break through as indicated with a mass spectrometer looking for the increase at mass 4 and also by monitoring the pressure increase. The nominal leak rate was determined at temperature and the "excess" leak rate was attributed to deuterium permeation. The calculations used to determine the desired data are shown below.

$$
J=A * D * L / s *\left(\sqrt{ } p_{1}-\sqrt{ } p_{2}\right)
$$

or when $\mathrm{p}_{2}$ is negligibly small as is the case for these tests:

$$
\mathrm{J}=\mathrm{A} * \mathrm{D} * \mathrm{~L} / \mathrm{s} * \bigvee_{\mathrm{p}_{1}}
$$

In addition, the steady state pressure rise allows calculation of $\mathrm{D}$.

$$
\mathrm{D}=\mathrm{s}^{2} /(6 \mathrm{t})
$$

In eq. $1-3, \mathrm{~J}$ is the steady state flux determined from the pressure rise and the calculated expansion volume, $\mathrm{D}$ the diffusivity, $\mathrm{L}$ the solubility, $\mathrm{s}$ is the sample thickness, $\mathrm{t}_{\ell}$ is the time lag determined from the data, $\mathrm{p}_{1}$ and $\mathrm{p}_{2}$ are the upstream (entrance side pressure) and downstream (exit side pressure) pressures, $\mathrm{A}$ is the sample area, and the product $\mathrm{D} * \mathrm{~L}$ is the permeability $(\mathrm{P})$ $[1,2,3]$

\section{Characterization Results}

Metallographic examination of the coated samples revealed microstructures typical of these types of coatings. All of the coatings exhibited uniform thickness. Photomicrographs of the coatings at low and high magnifications are shown in Fig. 2. The simple aluminide (Fig. 2a and b) coating exhibits the expected two layer microstructure. The outer layer is aluminum rich, approximately 50 atomic percent and the inner layer is an aluminum modified ferrite layer; this coating is consistent with that applied to magnesium and getter bed containers. The plasma sprayed aluminum coating (Fig. 2c and d) exhibits some fine porosity and oxides typical of this type of processing; this type of coating was applied to the TCON thermal cycling absorption process unit. The as-sprayed HVOF NiCoCrAlY (Fig. 2e and f) exhibits fine porosity and oxides that decorate the particle boundaries. This structure is also typical of coating processed using HVOF. The heat treated HVOF NiCoCrAlY (Fig. 2g and h) exhibits some pores and oxides. The coating shows a mixture of white dispersoids in a gray matrix. The coating contains a mixture of beta nickel aluminide $(\mathrm{NiAl})$ and gamma nickel aluminide $\left(\mathrm{Ni}_{3} \mathrm{Al}\right)$. The coating near the interface is denuded of the gray material. The platinized HVOF NiCoCrAlY (Fig. $2 \mathrm{i}$ and $\mathrm{j}$ ) is a new variation on a widely used coating. This coating microstructure has not been described previously. It exhibits a white zone at the surface with a similar structure below this platinum modified zone. The platinum aluminized HVOF NiCoCrAlY (Fig. 2k and 1) exhibits an expected three layer microstructure with an outer layer of nearly single phase gray (beta phase), an inter-diffusion zone and a structure similar to the heat treated HVOF coating below the modified layer. The aluminized HVOF NiCoCrAlY (Fig. $2 \mathrm{~m}$ and $\mathrm{n}$ ) exhibits two layers, an aluminum modified surface with a heat treated HVOF NiCoCrAlY substructure. The 
platinum aluminide (Fig 2o and p) exhibits a two layer structure with white spots of Pt-modified iron aluminide dispersiods in an iron aluminide matrix.

A coating coupon from a quality assurance sample for a magnesium bed is shown in Fig. 3 with micrographs of the coating shows a two layer structure comparable to that shown in Figure 2a.

The coatings were also characterized using scanning electron microscopy (SEM) with x-ray energy dispersion analysis (XEDA) in both qualitative and quantitative methods. The simple aluminide coated Type 316 Stainless Steel (SS) is shown in Fig. 4 with a typical outer surface XEDA plot shown in $4 \mathrm{~b}$ and two distinct phases are shown in Fig. $4 \mathrm{c}$ with the associated XEDA data for the scans. The dark phase contains more Al than the lighter gray phase.

The SEM micrograph and an XEDA scan for the plasma sprayed aluminum are shown in Fig. 5. The sample exhibits reasonable density and is nearly pure $\mathrm{Al}$, as was specified in the procurement documents.

The as sprayed HVOF NiCoCrAlY coated Type $316 \mathrm{SS}$ is shown in Fig. 6. The coating is uniform in composition as indicated by the XEDA results and the semi-quantitative data that were generated, a plot of the composition as a function of distance from the surface is shown in Fig. 6c.

The heat treated HVOF NiCoCrAlY coated Type 316 SS is shown in Fig. 7 with supporting SEM XEDA data in Figs 7c-7e. This coating exhibits the expected two phase structure clearly shown in Fig. 7b. The light areas are aluminum deficient. This aluminum concentration change is evident in the composition profile shown in Fig. 7e, where the interface exhibits a significant change in $\mathrm{Al}$ content. The microstructural change at the interface is caused by diffusion of the coating species into the substrate and of the substrate species into the coating. The denuded zone is typically on the order of 10-15 $\mu \mathrm{m}$ and can be seen on all of the HVOF NiCoCrAlY samples that were heat treated either intentionally or as part of the rest of the auxiliary coating processes; the original interface is decorated with oxides used to prepare the substrate.

The platinized HVOF NiCoCrAlY coating is shown in Fig. 8. As expected, the Pt content changes rapidly from the surface inward with only a small (non-quantified) amount indicated about $50 \mu \mathrm{m}$ from the surface. No Pt was detected in the center of the coating, Fig. 8e.

The platinum aluminized HVOF NiCoCrAlY sample is shown in Fig. 9. This sample exhibits a number of different features, including a white etching zone rich in Pt, a featureless interdiffusion layer of $\mathrm{Pt}$ and $\mathrm{Al}$ enriched NiCoCrAlY and a secondary interdiffusion zone, followed by a typical heat treated NiCoCrAlY structure.

The aluminized HVOF NiCoCrAlY is shown in Fig. 10. The outer portion of the coating is uniform gray surface and is rich in Al. This composition is likely beta NiAl and is comparable to the dark gray spots shown in Fig. 10c, except the Ni peak is slightly higher with a reduction in the $\mathrm{Al}$ peak. The light gray regions are lower in $\mathrm{Al}$ than the gray regions. 
The platinum aluminized 316 SS sample is shown in Fig. 11. This sample exhibits a platinum rich surface, some platinum rich particles and a significant interdiffusion zone. The interdiffusion zone was much greater than expected. The platinum and aluminum concentrations can be seen in Fig. 11g, the composition profile of the coating, note that the Pt is enriched at the surface and drops off rapidly about $50 \mu \mathrm{m}$ in from the surface.

\section{Permeation Test Results}

Disk samples were loaded between copper gaskets and placed between standard all-metal vacuum flanges, i.e., conflat flanges. This design was intended to allow for maximum sample geometry flexibility. The samples exhibited inconsistent sealing though, and modifications to the gaskets were attempted in order to improve the viability of the samples. A schematic of the sample loading is shown in Fig. 12. A machined gasket schematic and the new sample geometry are also indicated. Due to the long lead and high cost of the samples, procuring new coated samples for testing this past year was not considered a viable option. The problems with sample sealing was not considered insurmountable since several disk samples with copper gaskets were tested that had acceptable leak rates.

As it became evident that sample sealing would continue to be an issue, alternative flanges and gaskets were designed and tested. A swagelock gasket assembly was fabricated and samples were leak tested by the high pressure laboratory. During the course of leak testing, the sample was tightened sufficiently tight to actually cut the coated stainless steel disk. Other samples were loaded using this fixture and the leak rates were too high to warrant testing. Consequently, this design was not considered further.

Table 2 shows the list of samples and tests that were completed. The relevant permeation data are presented. The permeation data were extracted from the pressure-time data by determining the time to break through and the rate of pressure increase, as described previously. Typical data curves from a bare sample and a coated sample that both exhibit the expected characteristics are shown in Fig. 13. The temperatures and pressures were changed to shorten the test times and also to provide additional data so the permeation data could be defined as a function of temperature and pressure.

Table 2. Permeation tested samples conditions and raw data

\begin{tabular}{|l|l|l|l|l|}
\hline Sample & \multicolumn{3}{|c|}{ Conditions } & \multicolumn{1}{l|}{ Results } \\
& Pres. (Torr) & \multicolumn{1}{l|}{ Temp $\left({ }^{\circ} \mathrm{C}\right)$} & $\mathrm{t}_{\ell}(\mathrm{s})$ & $\mathrm{dP} / \mathrm{dt}(\mathrm{Torr} / \mathrm{s})$ \\
\hline Bare 304 SS & 200 & 300 & 12122 & $4.78 \times 10^{-6}$ \\
\hline Bare 304 SS & 400 & 300 & Inconclusive \\
\hline HT NiCoCrAlY & 200 & 200 & 121649 & $1.13 \times 10^{-6}$ \\
\hline PS - Al & 200 & 300 & Inconclusive \\
\hline Pt-Al sample \#9 & 200 & 200 & 301033 & $1.13 \times 10^{-5}$ \\
\hline AS NiCoCrAlY & \multicolumn{4}{|l|}{ Leak rate too high to start test } \\
\hline Aluminide & \multicolumn{4}{|l|}{ Leak rate too high to start test } \\
\hline Pt-Aluminide & \multicolumn{4}{l}{ Leak rate too high to start test } \\
\hline
\end{tabular}


The raw data were used to determine the actual diffusivity and permeability values of the coated and bare samples, Table 3 . These were compared to previous permeation data for bare stainless steel (2). The permeation data that were gathered, appear to be a reasonable estimate of the diffusivity for stainless steel with the results being in the same order of magnitude as that calculated using Ref. 2. On the other hand, the permeability data appear to exhibit excessive scatter within sample runs and between the samples. An improved test methodology should increase the reliability of the data.

Table 3. Diffusivity and Permeability data extracted from raw data.

\begin{tabular}{|l|l|l|l|}
\hline Sample & Temp $\left({ }^{\circ} \mathrm{C}\right)$ & Diffusivity $\left(\mathrm{cm}^{2} / \mathrm{s}\right)$ & Permeability $\left(\mathrm{cc}(\mathrm{NPT}) / \mathrm{cm}^{*} \mathrm{~s}^{*} \sqrt{\mathrm{atm}}\right.$ \\
\hline Bare 304 SS & 300 & $3.5 \times 10^{-8}$ & $3.4 \times 10^{-11}$ \\
\hline HT NiCoCrAlY & 200 & $3.54 \times 10^{-9}$ & $1.06 \times 10^{-10}$ \\
\hline Pt-A1 sample \#9 & 200 & $1.43 \times 10^{-9}$ & $1.06 \times 10^{-10}$ \\
\hline Bare Ref. 1 & 200 & $5.14 \times 10^{-9}$ & $1.48 \times 10^{-9}$ \\
\hline Bare Ref. 1 & 300 & $5.64 \times 10^{-8}$ & $2.11 \times 10^{-8}$ \\
\hline
\end{tabular}

\section{Discussion}

The permeation apparatus and test methodology produced more variation in results between samples than expected. The literature review that was conducted indicated that the sealing method proposed would be adequate. It appeared to work for samples which were inherently flat and smooth, i.e., uncoated samples but could not adequately seal samples which were curved and rough due to the coating process. A new sample geometry in which the sample is welded to the vacuum flange is being produced for baseline testing of the materials of construction, substrate and coating, that are used for the magnesium and uranium bed containers.

The reliability of the mass spectrometers resulted in significant delays in testing. The mass spectrometers were sent back to the vendor several times for repair with each down time lasting approximately one month.

Additional attempts will be made to test the existing samples using a gold plated copper gasket which demonstrated improved sealing capability over copper gaskets. The emphasis for the coming tests will be on the existing plant materials rather than new development coatings.

\section{Conclusions}

The coatings exhibited the expected microstructure with a few exceptions. Excessive interdiffusion for the platinum aluminide coating was unexpected. The non-uniformity of the platinum on the platinized HVOF NiCoCrAlY coating was rather surprising.

Sample sealing and equipment failures consumed far more assets, time, and money than was suggested by the articles consulted during the permeation facility design and sample selection. Additional testing to obtain true calibrated expansion volumes will be useful to obtain more quantitative data for comparison to reference data. 
A new sample geometry and regimen in which disks or other geometric shapes are welded into the conflat flanges will minimize the issues related to sample sealing that had such an adverse impact on this series of tests.

\section{Acknowledgements}

This task could not have been completed without the assistance of G. Creech, E. Clark, Z. Nelson, V. Timmerman, and J. Durden.

\section{References}

1. "Hydrogen transport in austenitic stainless steel", M. R. Louthan, Jr. and R. G. Derrick, Corrosion Science, Vol 15, pp. 565 - 577, 1975.

2. "Tritium permeation barriers for fusion technology", A. Perujo, K. S. Forcey, Fusion Engineering and Design, 28, pp. 252-257, 1995.

3. "Tritium permeation and related studies on barrier treated 316 stainless steel", E. R. Gilbert, R. P. Allen, D. L. Baldwin, R. D. Bell, J. L. Brimhall, R. G. Clemmer, S. C. Marschman, M. A. McKinnon, R. E. Page, and H. G. Powers, Fusion Tech. Vol 21, pp 739-744, 1992.

4. "Studies on the permeation of hydrogen and tritium through heat resistant alloys", A. Schmidt, F. Verfuss, E. Wicke, Journal of Nuclear Materials, 131, pp. 247-260, 1985.

5. "Tritium/hydrogen barrier development", G.W. Hollenberg, E.P. Simonen, G. Kalinin, A. Terlain, Fusion Engineering, 28, pp 190-208, 1995. 


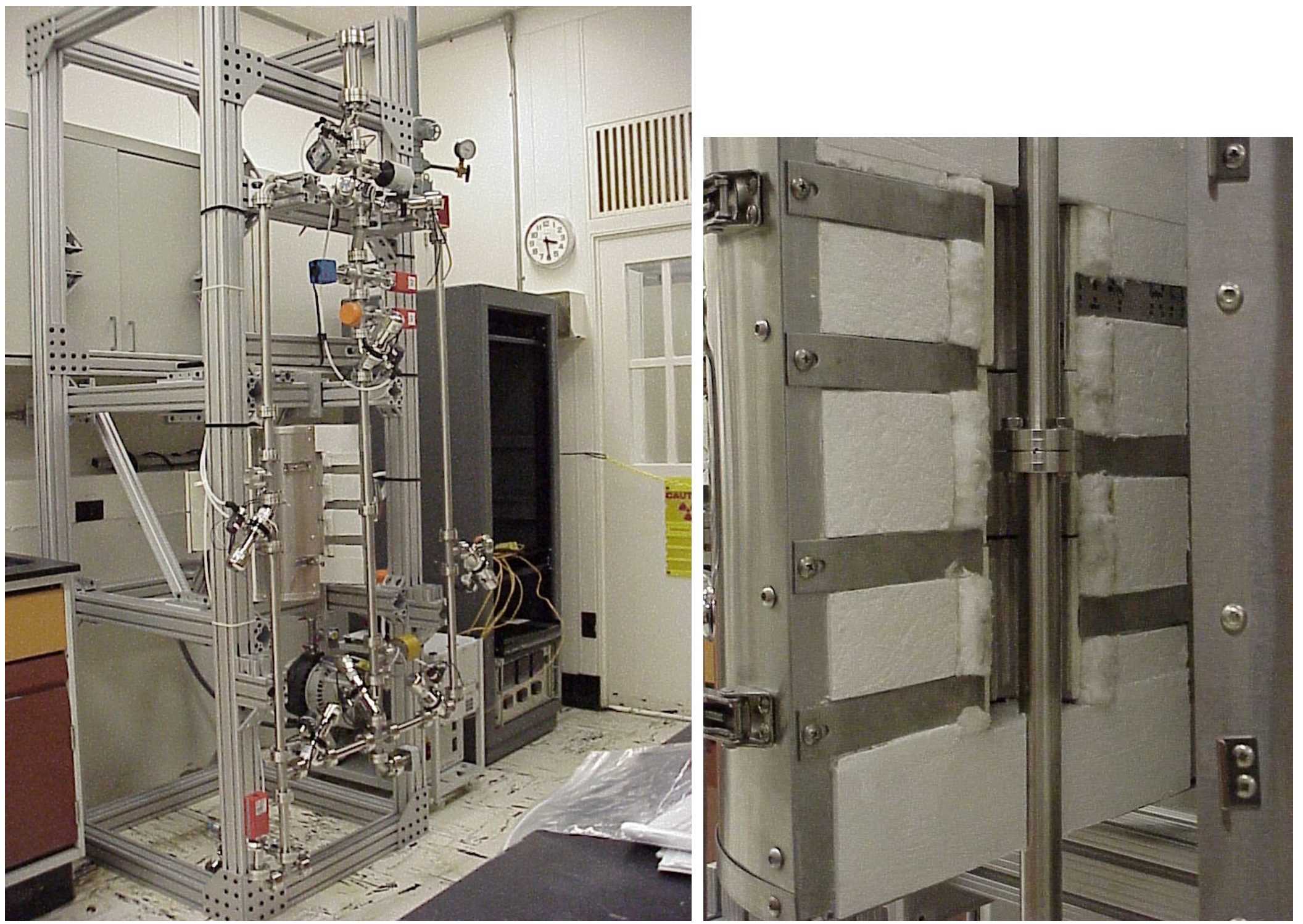

(a) overall

(b) close-up of furnace and sample area

Fig. 1. Photographs of the permeation test facility. (a) overall (b) close-up of furnace and sample area. 
WSRC-TR-2004-00040

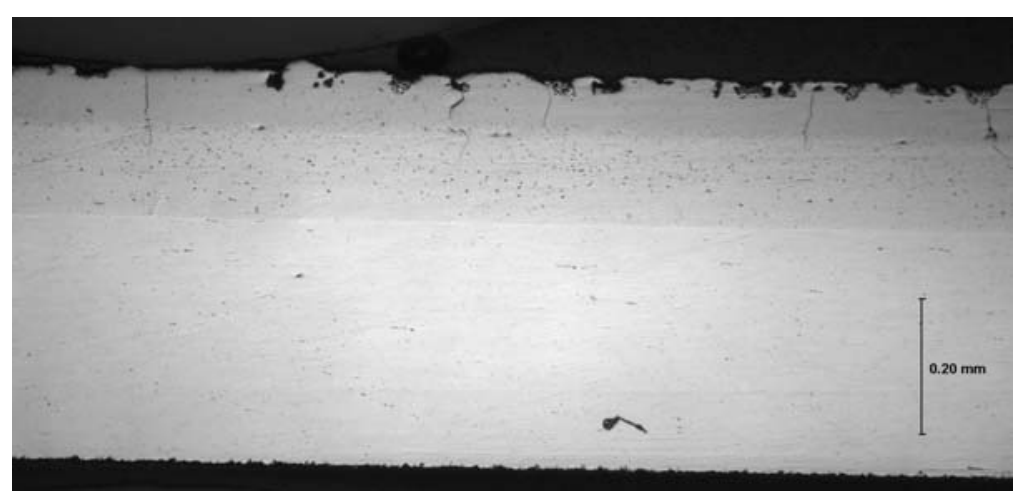

(a) simple aluminide at $100 \mathrm{X}$

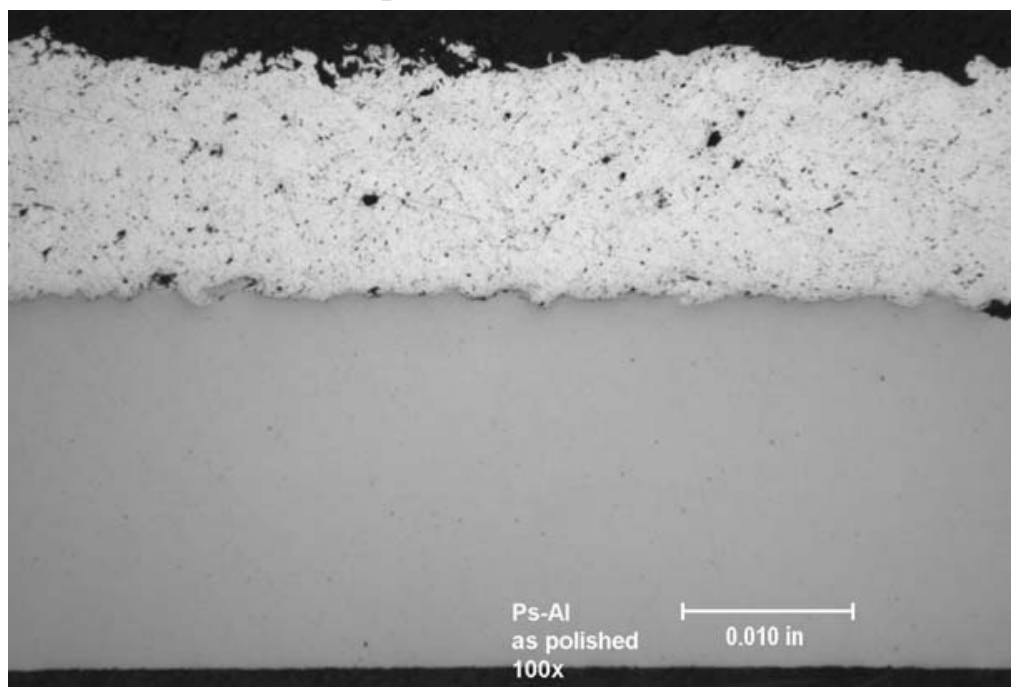

(c) plasma sprayed aluminum at $100 \mathrm{X}$
N/A

(b) simple aluminide at $500 \mathrm{X}$

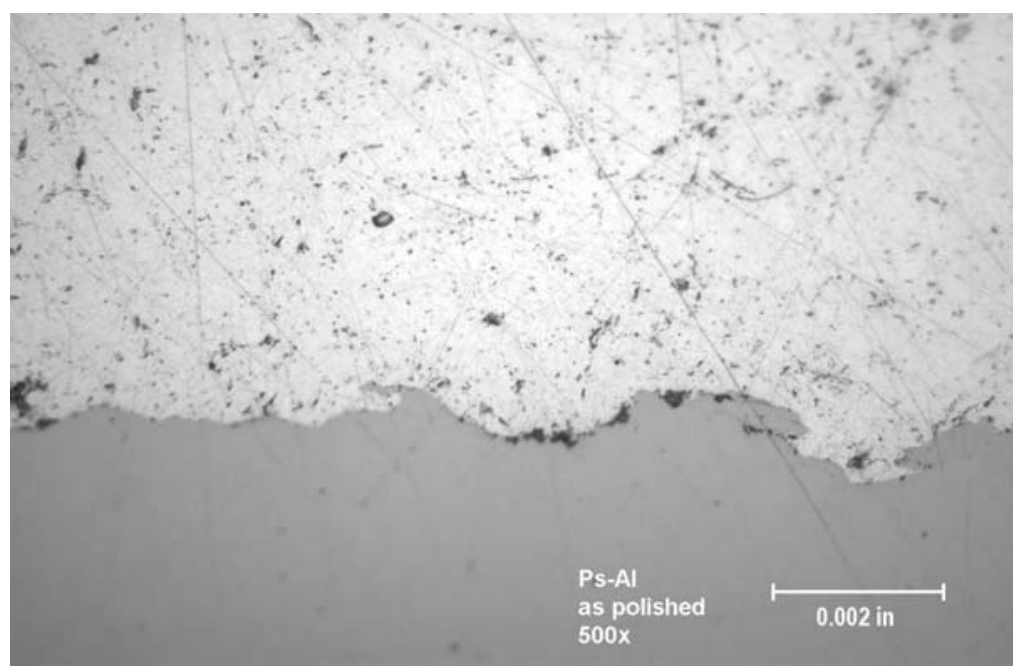

(d) plasma sprayed aluminum at 500X

Fig. 2. Photomicrographs of (a) Simple aluminide at 100X (b) Simple aluminide at 500X (commonly used on getter beds and magnesium beds), (c) Plasma sprayed aluminum at 100X (d) Plasma sprayed aluminum at 500X (used for the TCON TCAP) (e) As sprayed HVOF NiCoCrAlY at 100X (f) As sprayed HVOF NiCoCrAlY at 500X (g) Heat treated HVOF NiCoCrAlY at 100X (h) heat treated HVOF NiCoCrAlY at 100X (i) Platinized HVOF NiCoCrAlY at 100X (j) Platinized HVOF at 500X (k) Platinum aluminized HVOF NiCoCrAlY at 100X(l) Platinum aluminized HVOF NiCoCrAlY at 500X (m) Aluminized HVOF NiCoCrAlY at 100X (n) Aluminized HVOF NiCoCrAlY at 500X (o) Platinum aluminide at 100X and (p) Platinum aluminide at 500X. 
WSRC-TR-2004-00040

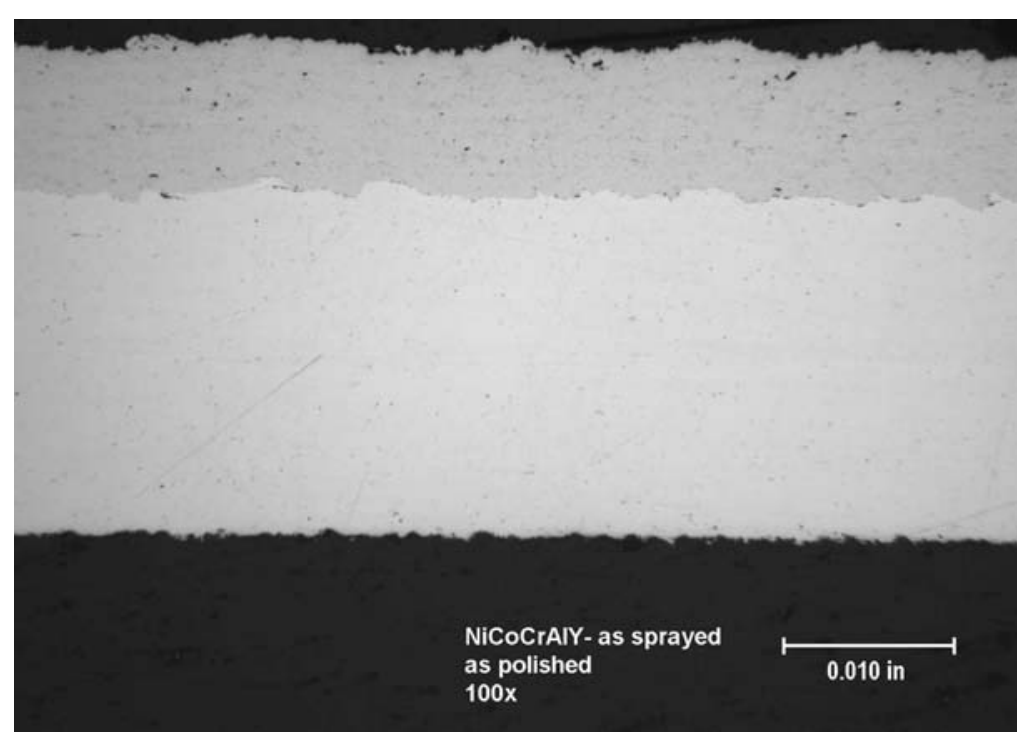

(e) As sprayed HVOF NiCoCrAlY at 100X

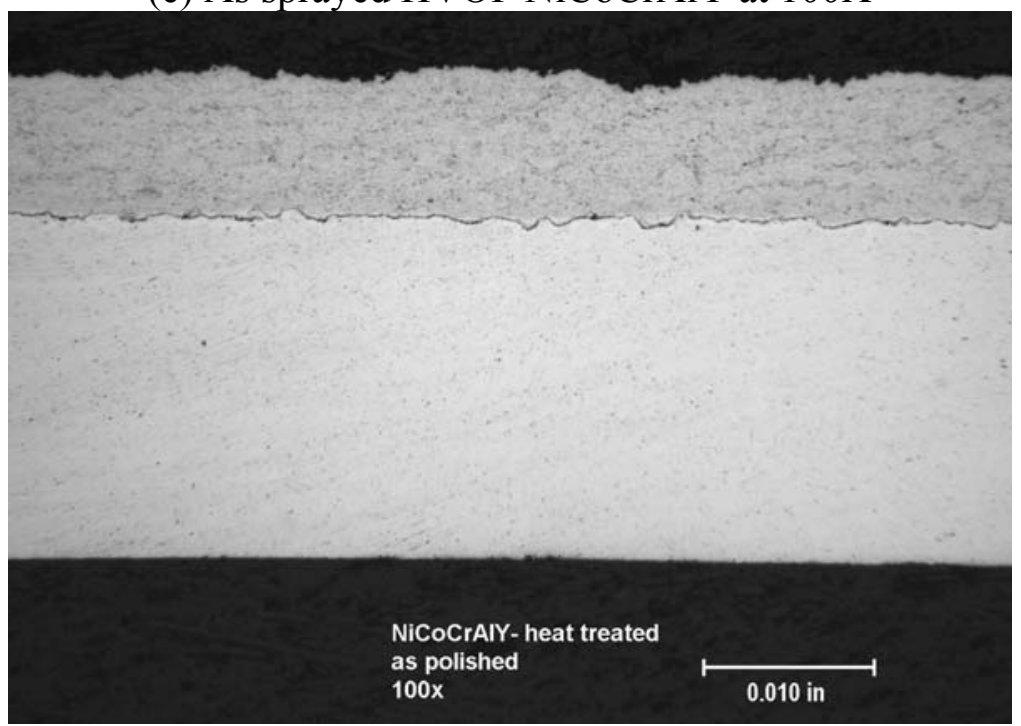

(g) Heat treated HVOF NiCoCrAlY at $100 \mathrm{X}$
Page 10

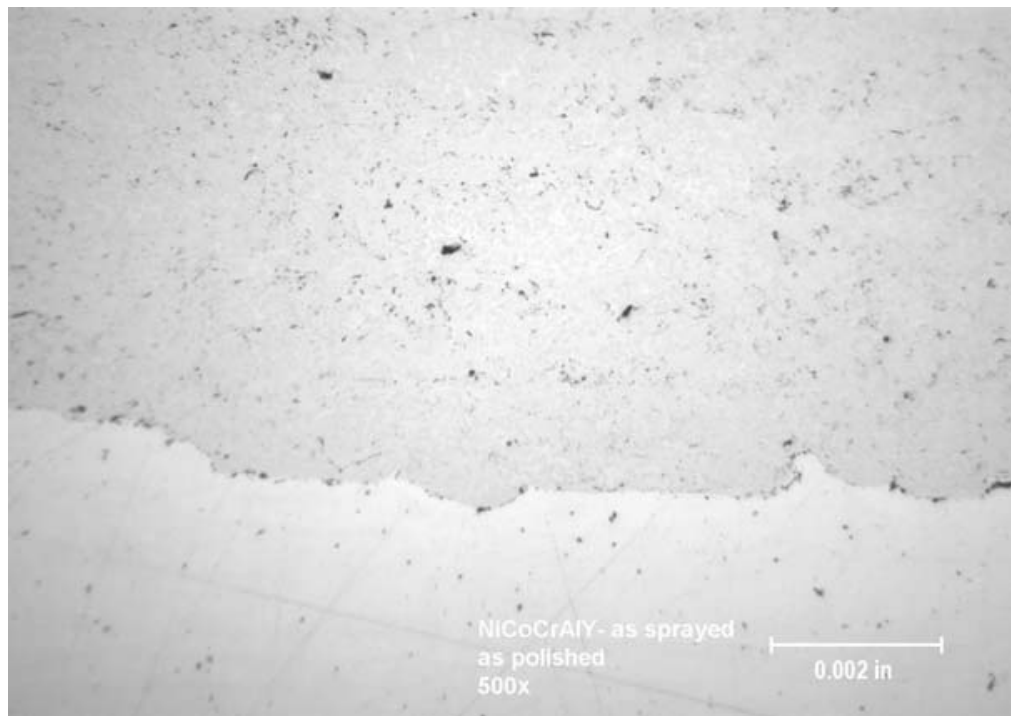

(f) As sprayed HVOF NiCoCrAlY at 500X

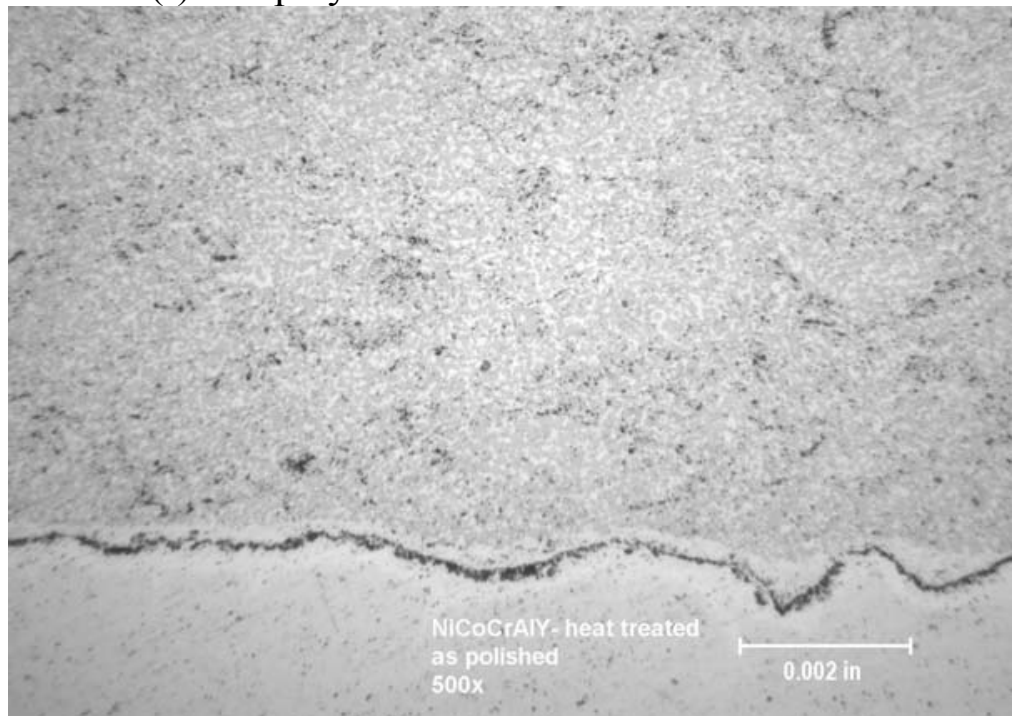

(h) Heat treated HVOF NiCoCrAlY at 100X

Fig. 2 (cont). Photomicrographs of (e) As sprayed HVOF NiCoCrAlY at 100X (f) As sprayed HVOF NiCoCrAlY at 500X (g) Heat treated HVOF NiCoCrAlY at 100X (h) heat treated HVOF NiCoCrAlY at 100X 
WSRC-TR-2004-00040

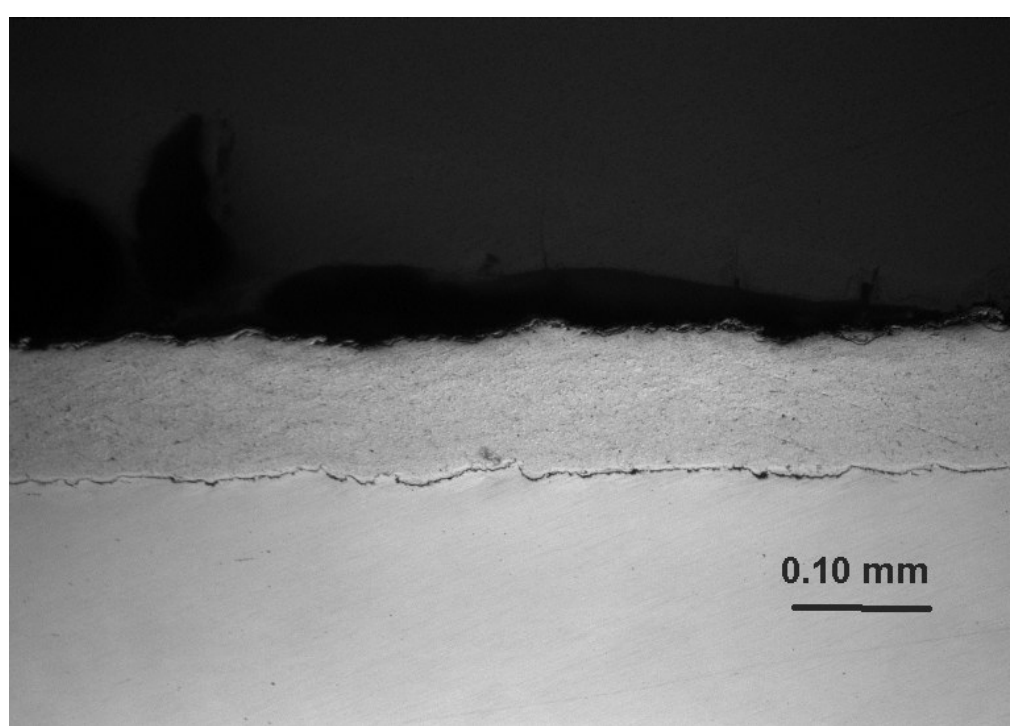

(i) Platinized HVOF NiCoCrAlY at 100X

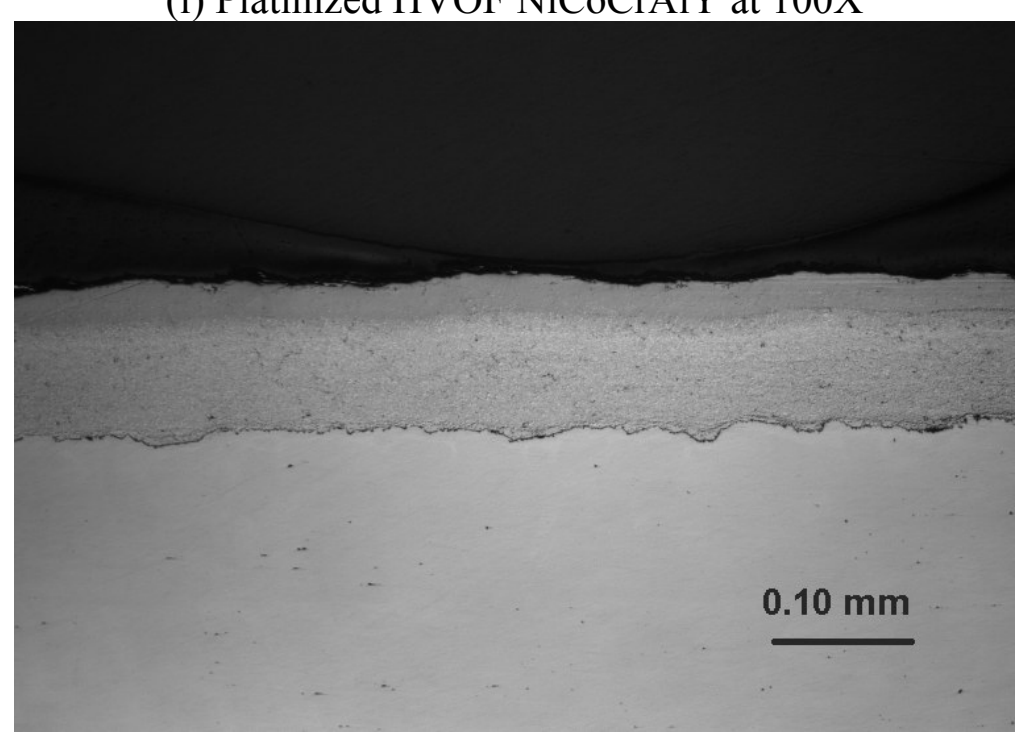

(k) Platinum aluminized HVOF NiCoCrAlY at 100X

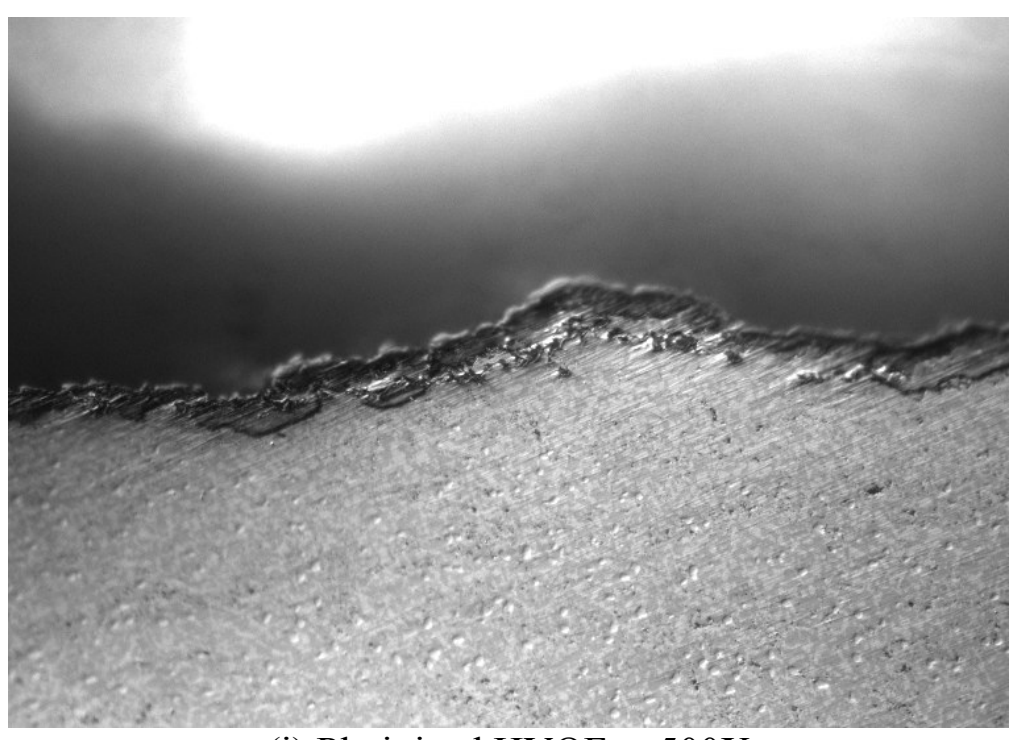

(j) Platinized HVOF at 500X

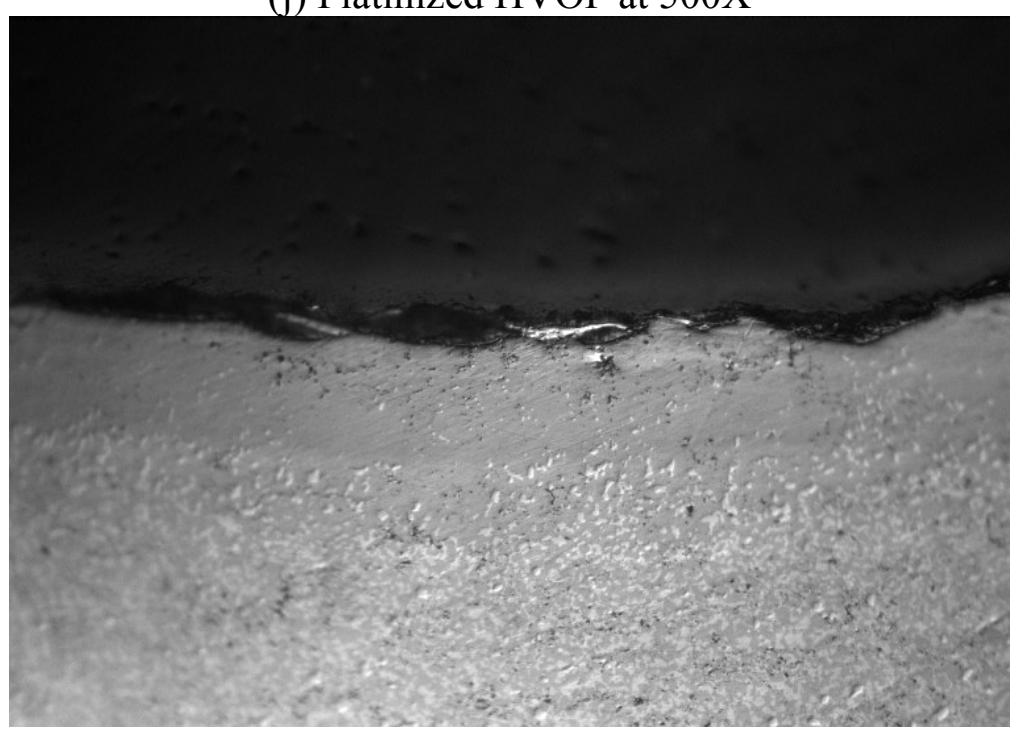

(1) Platinum aluminized HVOF NiCoCrAlY at 500X

Fig. 2 (cont). Photomicrographs of (i) Platinized HVOF NiCoCrAlY at 100X (j) Platinized HVOF at 500X (k) Platinum aluminized HVOF NiCoCrAlY at 100X (1) Platinum aluminized HVOF NiCoCrAlY at 500X 
WSRC-TR-2004-00040

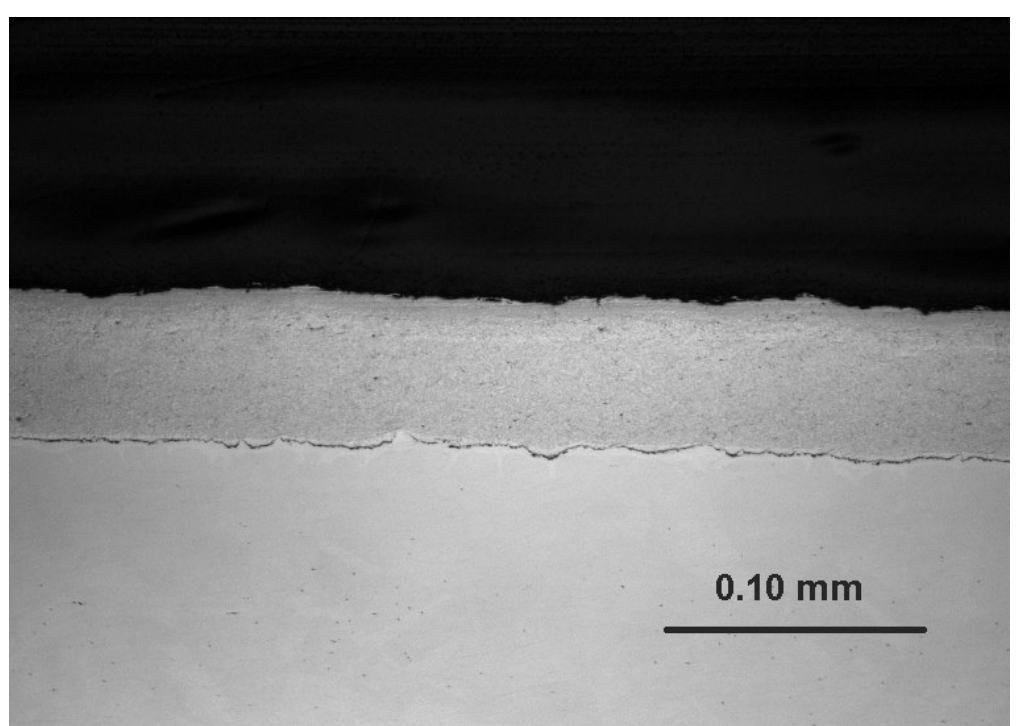

(m) Aluminized HVOF NiCoCrAlY at 100X

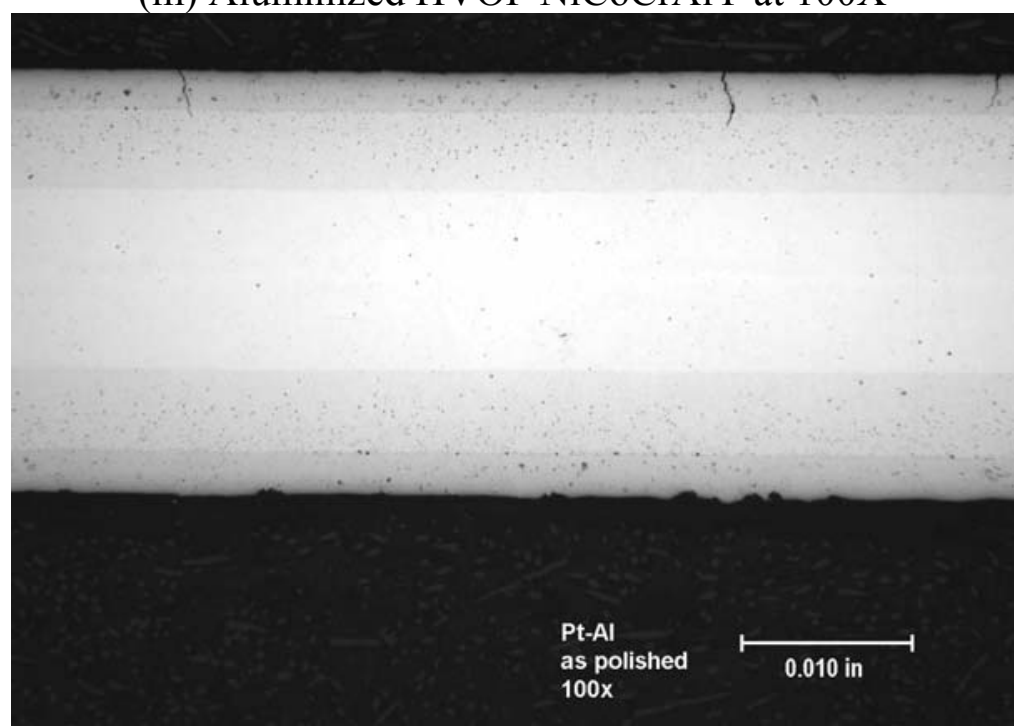

(o) platinum aluminide at $100 \mathrm{X}$
Page 12

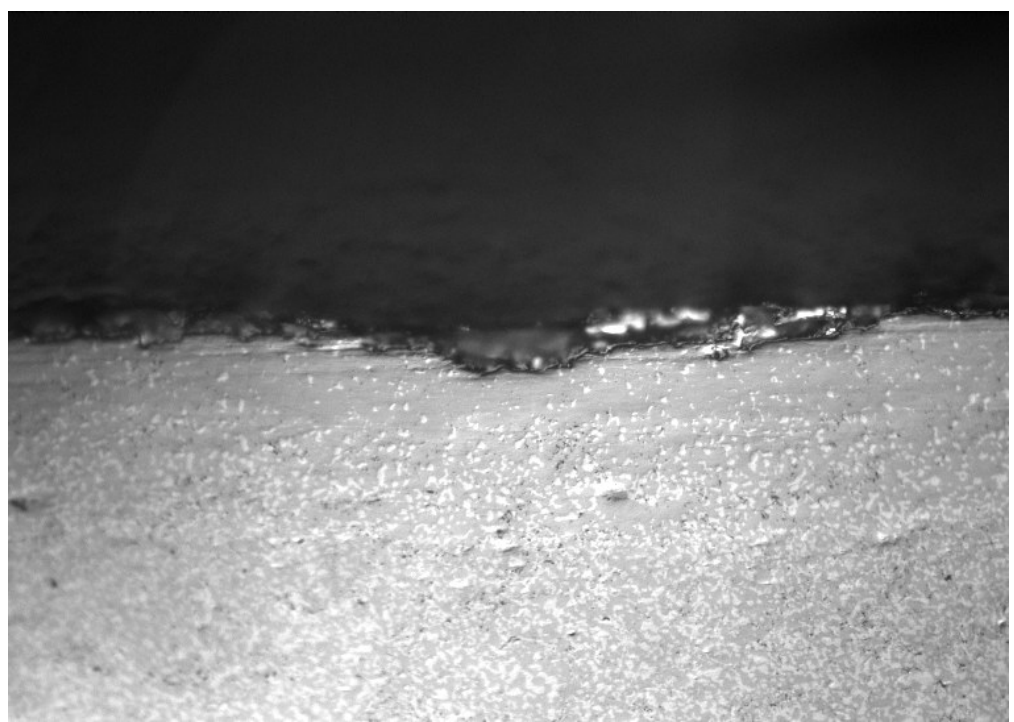

(n) Aluminized HVOF NiCoCrAlY at 500X

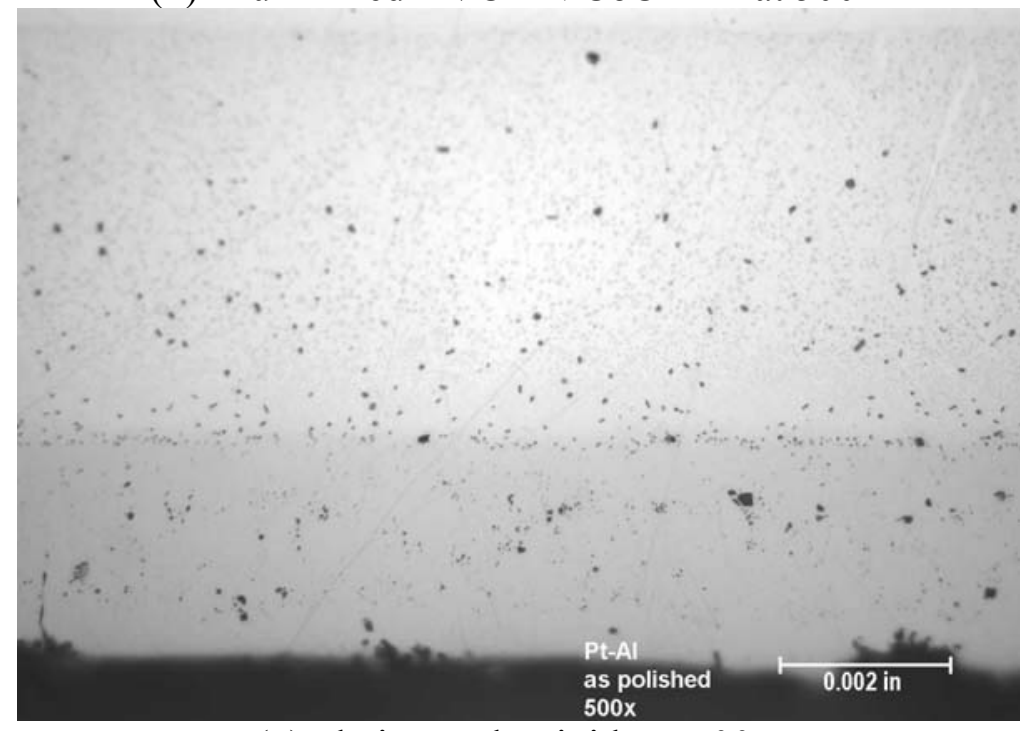

(p) platinum aluminide at $500 \mathrm{X}$

Fig. 2 (cont). Photomicrographs of (m) Aluminized HVOF NiCoCrAlY at 100X (n) Aluminized HVOF NiCoCrAlY at 500X (o) platinum aluminide at $100 \mathrm{X}$ and $(\mathrm{p})$ platinum aluminide at 500X. 
WSRC-TR-2004-00040
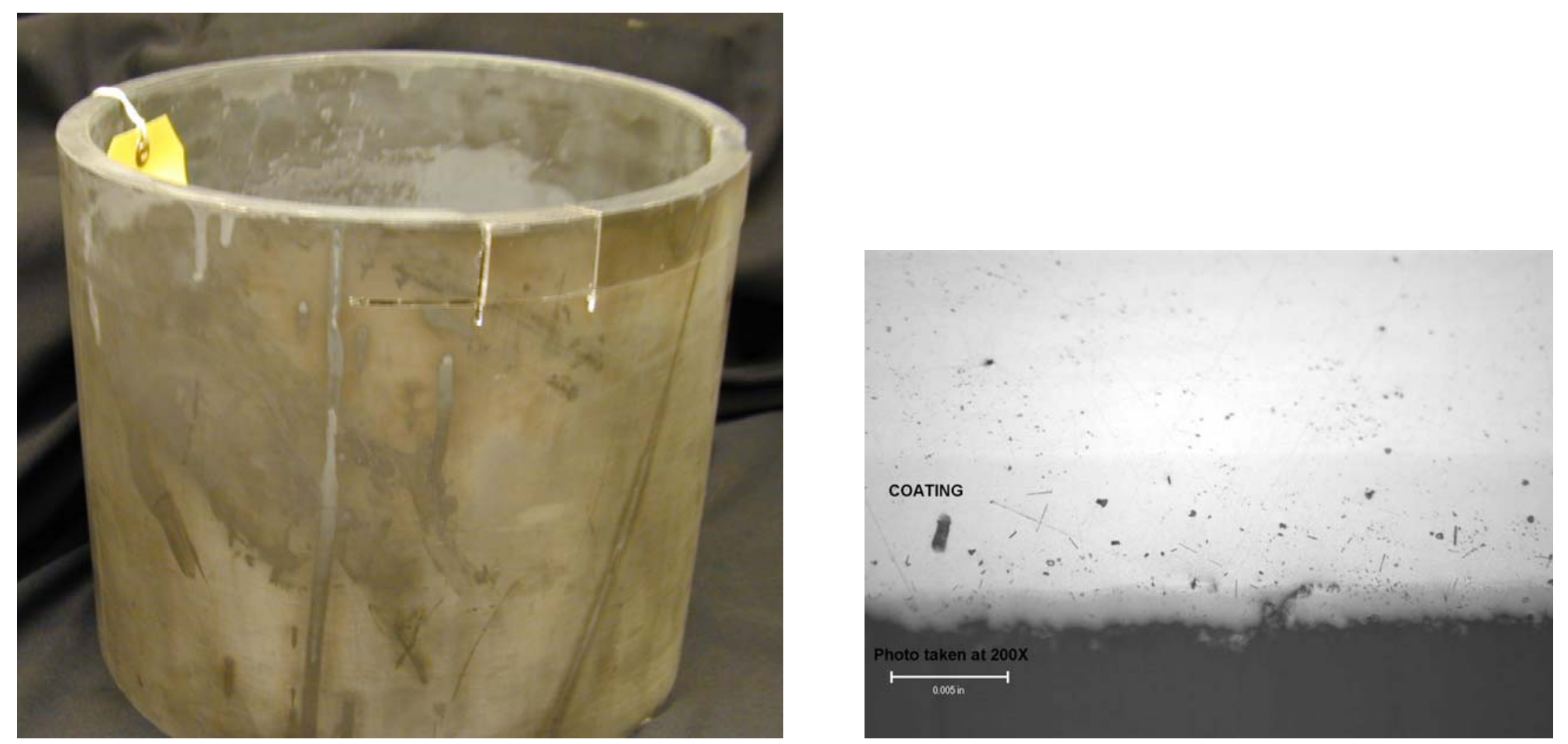

Fig. 3. Coating coupon from a magnesium bed container (a) overall view (b) metallographic cross-section showing two layer structure.

Page 13 


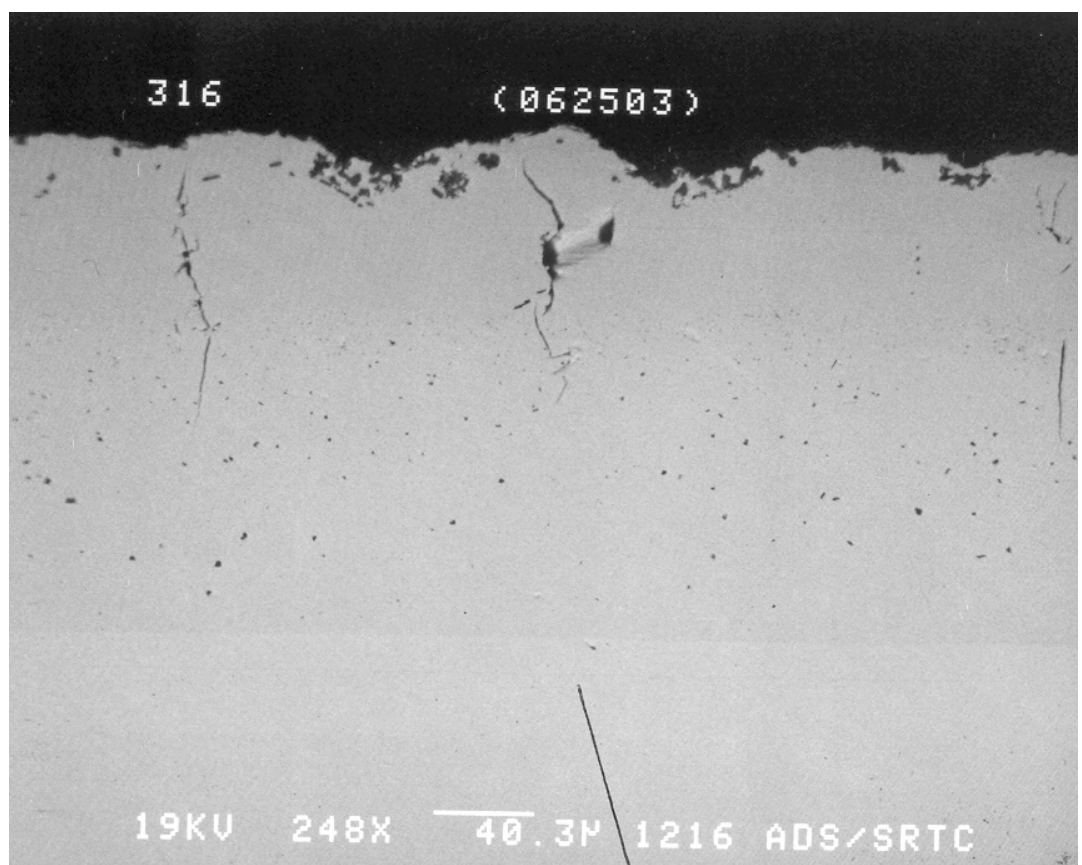

(a) SEM micrograph of overall coating

Thermo NORAN

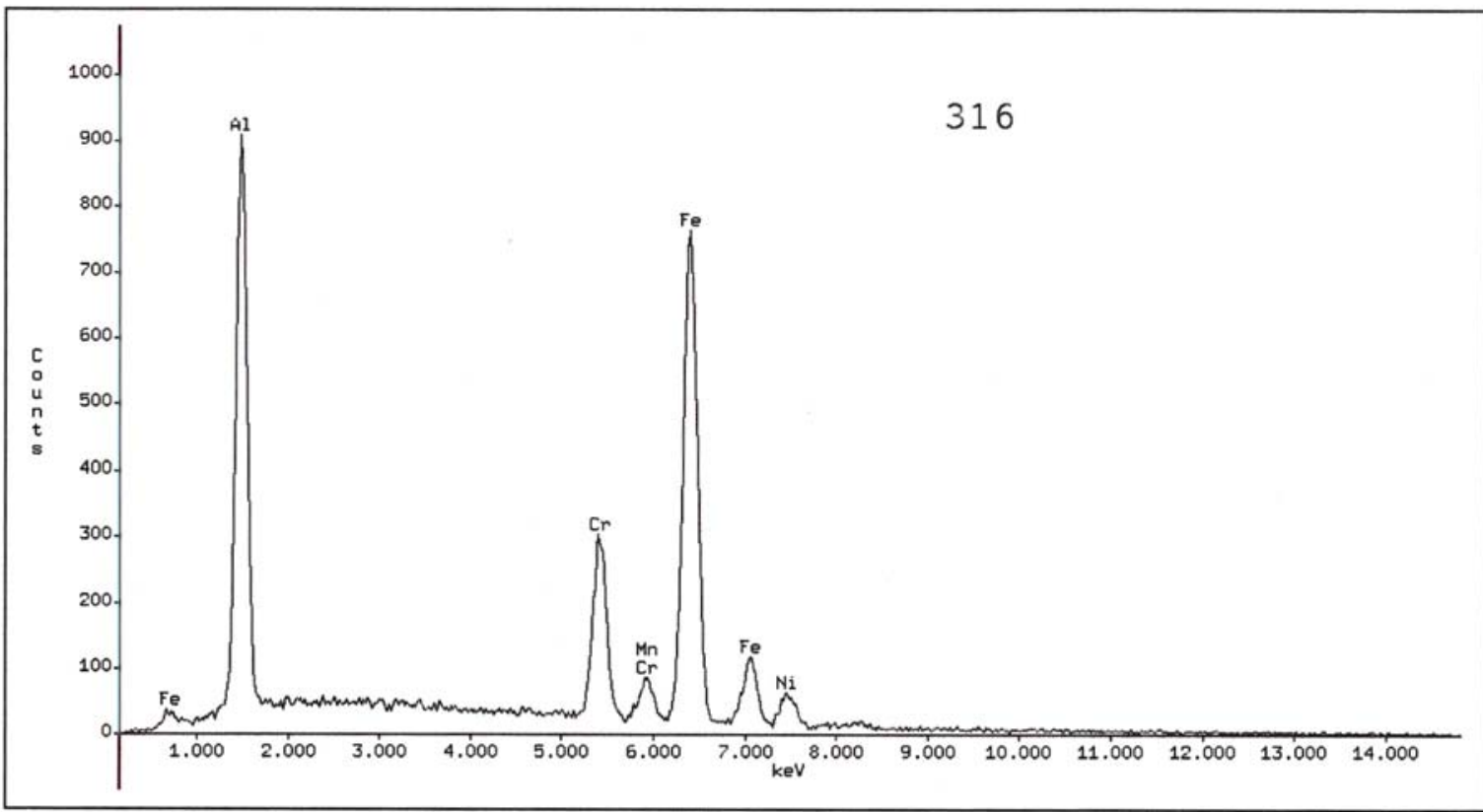

$316(062503) \quad$ PHOTO-1224 SPOT-5

Accelerating Voltage: $25 \mathrm{KeV}$

Take Off Angle: $10.0806^{\circ}$

Live Time: 19.47 seconds

Dead Time: 2.826 seconds

(b) XEDA spectrum of outer coating

Fig. 4. Simple aluminide coated 316 SS (a) SEM micrograph of overall coating (b) XEDA spectrum of outer region of coating (c) SEM micrograph showing interdiffusion zone (d) XEDA spectrum of dark spots in Fig. 4c. (e) XEDA spectrum of light gray areas in Fig. 4c. 


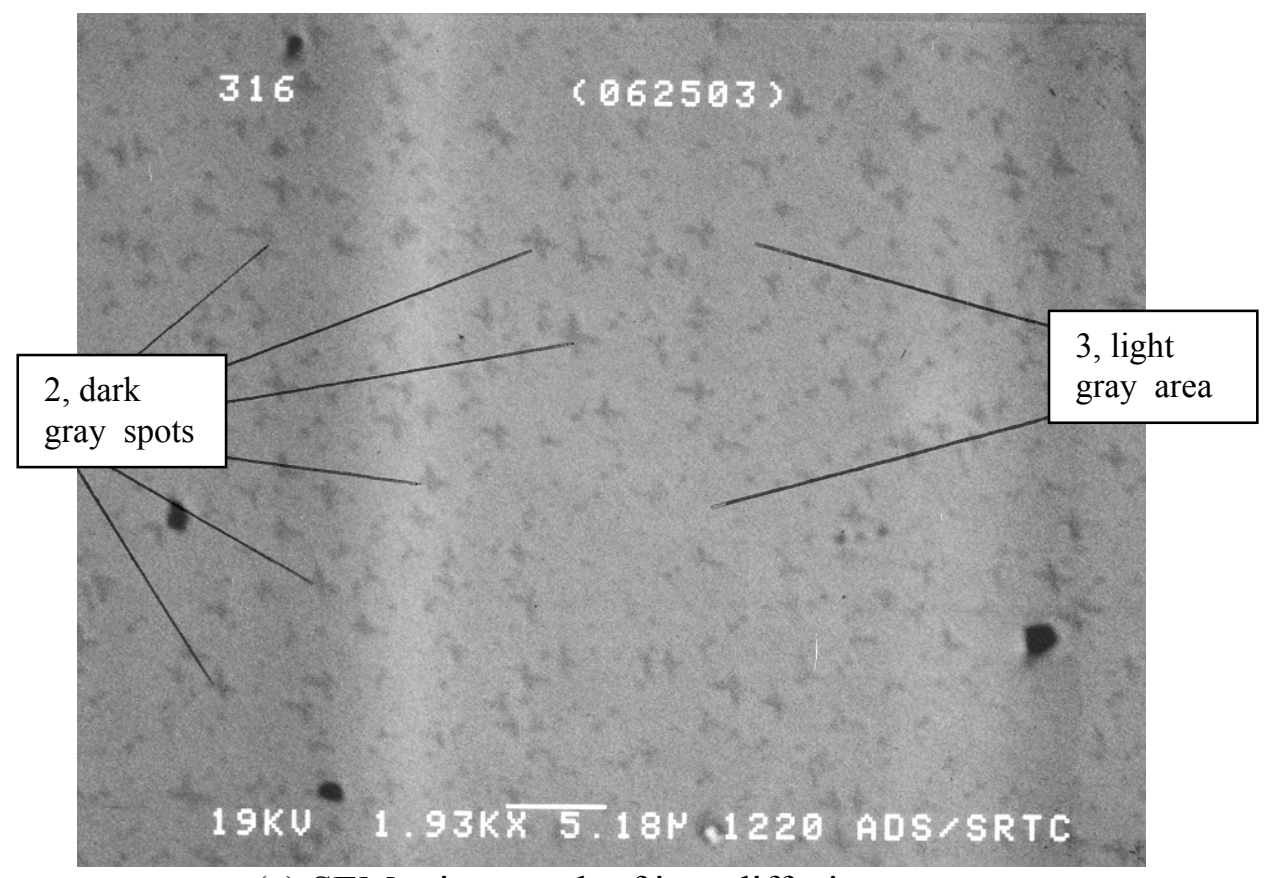

(c) SEM micrograph of interdiffusion zone

ThermoNORAN

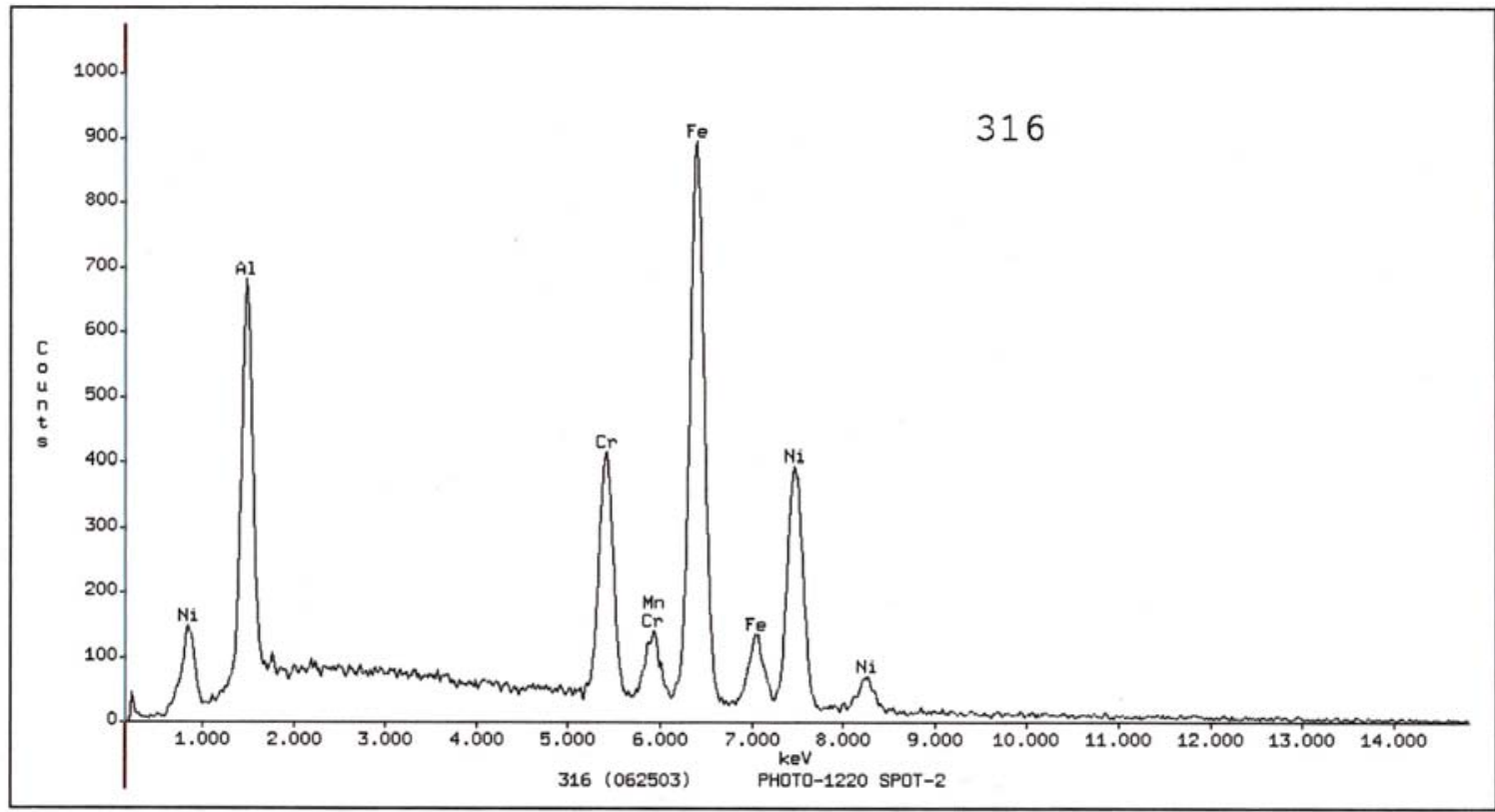

316 (062503) PHOTO-1220 SPOT-2

Accelerating Voltage: $25 \mathrm{KeV} \quad$ Take Off Angle: $10.0806^{\circ} \quad$ Live Time: 28.51 seconds $\quad$ Dead Time: 4.328 seconds

(d) XEDA spectrum of dark gray spots in Fig. 4c

Fig. 4. (cont.) Simple aluminide coated 316 SS (c) SEM micrograph showing interdiffusion zone (d) XEDA spectrum of dark spots in Fig. 4c. (e) XEDA spectrum of light gray areas in Fig. $4 c$. 
ThermoNORAN

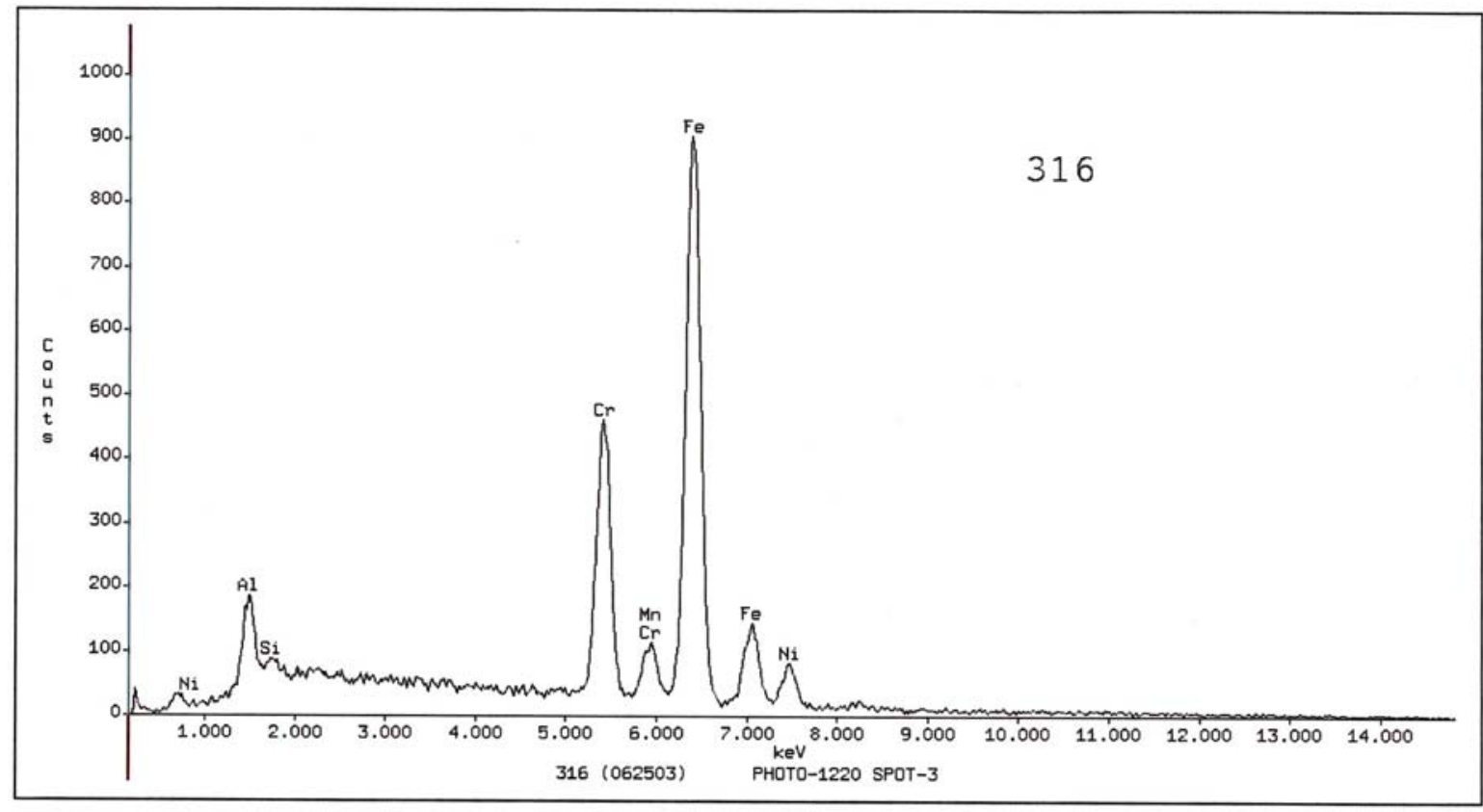

$316(062503) \quad$ PHOTO-1220 SPOT-3

Accelerating Voltage: $25 \mathrm{KeV}$ Take Off Angle: $10.0806^{\circ} \quad$ Live Time: 20.73 seconds Dead Time: 3.097 seconds

(e) XEDA spectrum of light gray areas in Fig. 6c

Fig. 4. (cont.) Simple aluminide coated 316 SS (e) XEDA spectrum of light gray areas in Fig. 4c. 


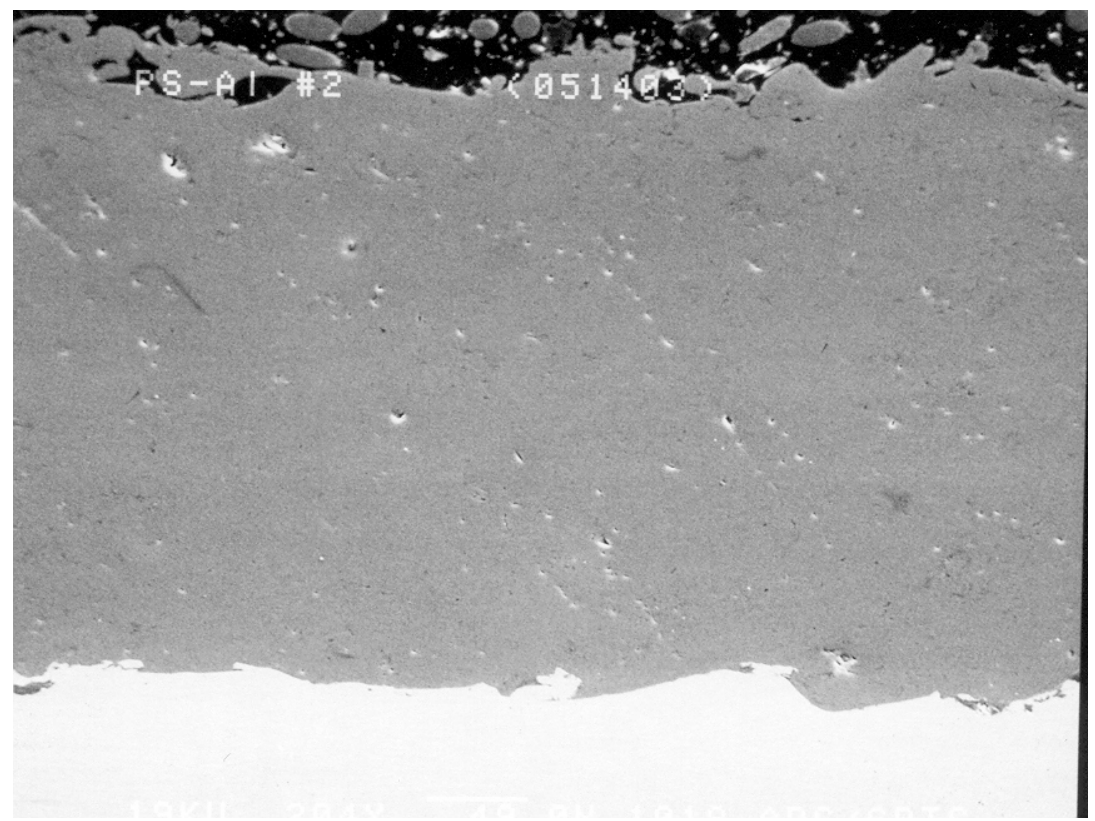

(a) SEM micrograph of coating

Thermo NORAN

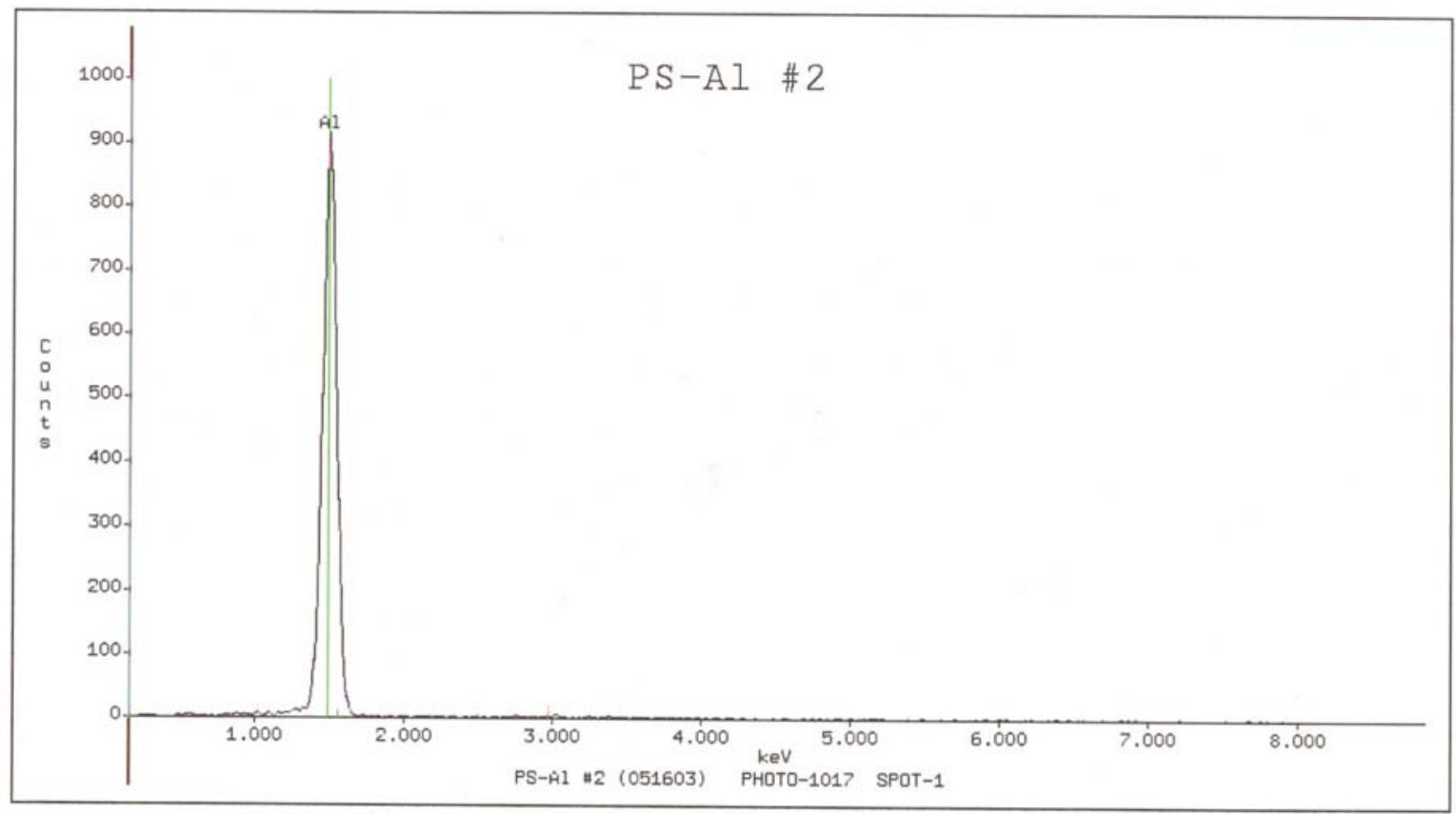

PS-Al \#2 (051603) PHOTO-1017 SPOT-1

Accelerating Voltage: $19 \mathrm{KeV}$

(b) typical XEDA spectrum of coating

Fig. 5. Plasma sprayed aluminum on 316 SS (a) SEM micrograph of coating and (b) typcial XEDA spectrum of coating 


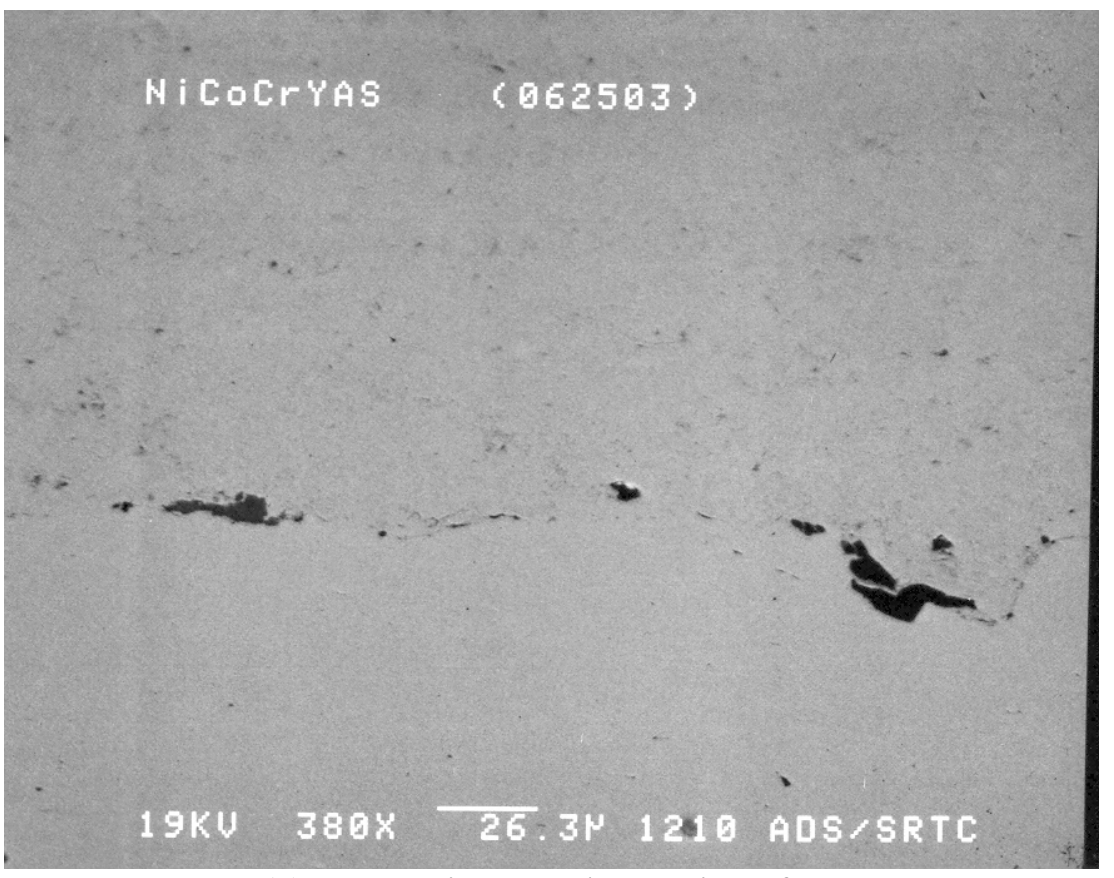

(a) SEM micrograph near interface

Thermo NORAN

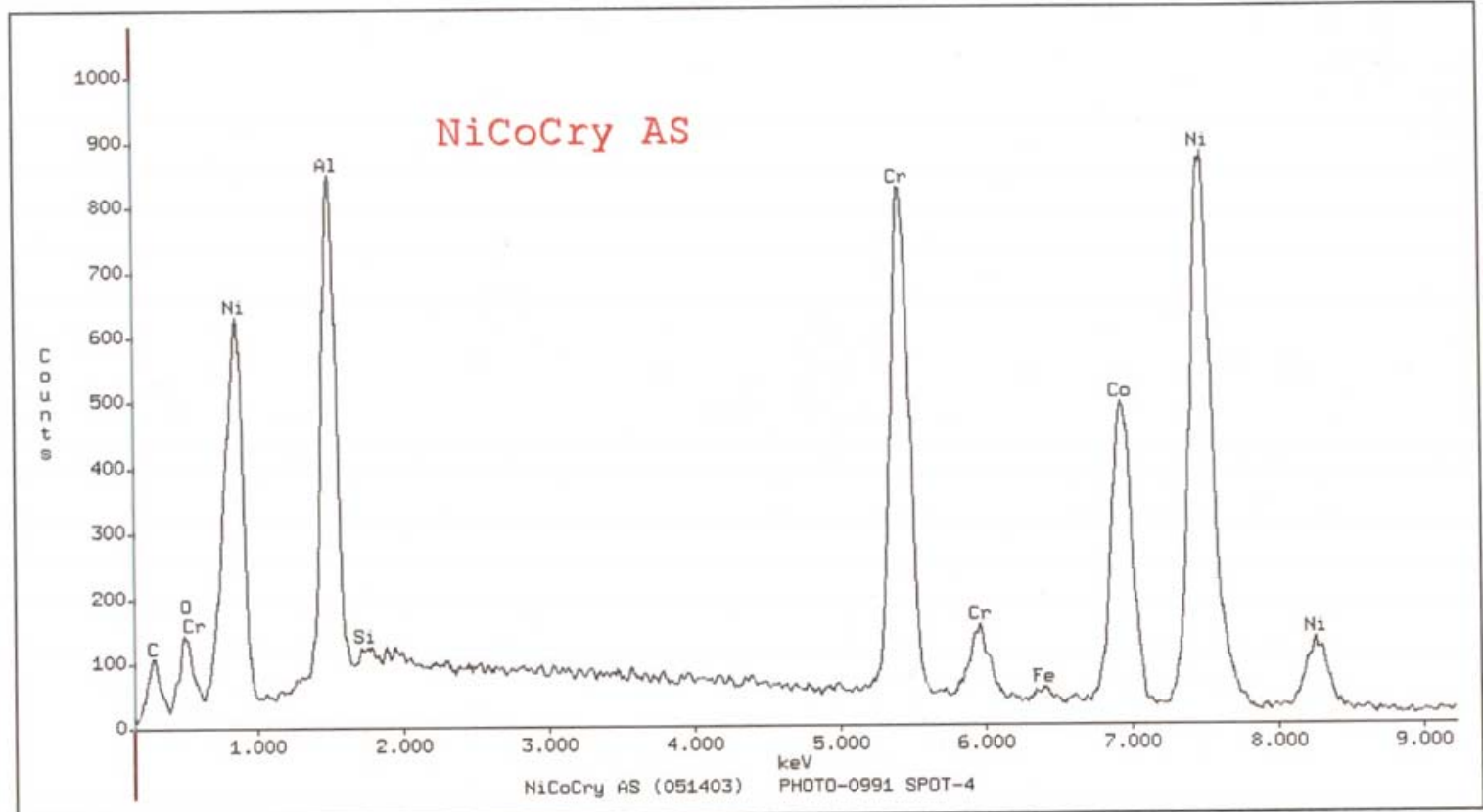

NiCoCry AS (051403) PHOTO-0991 SPOT-4

Accelerating Voltage: $19 \mathrm{KeV} \quad$ Take Off Angle: $25.7307^{\circ} \quad$ Live Time: 58.5 seconds

Dead Time: 12.074 seconds

(b) Typical XEDA spectrum

Fig. 6. As-sprayed HVOF NiCoCrAlY (a) SEM micrograph near interface (b) Typical XEDA spectrum (c) coating composition profile with base metal on left. 


\section{Composition profile of as sprayed NiCoCrAIY}

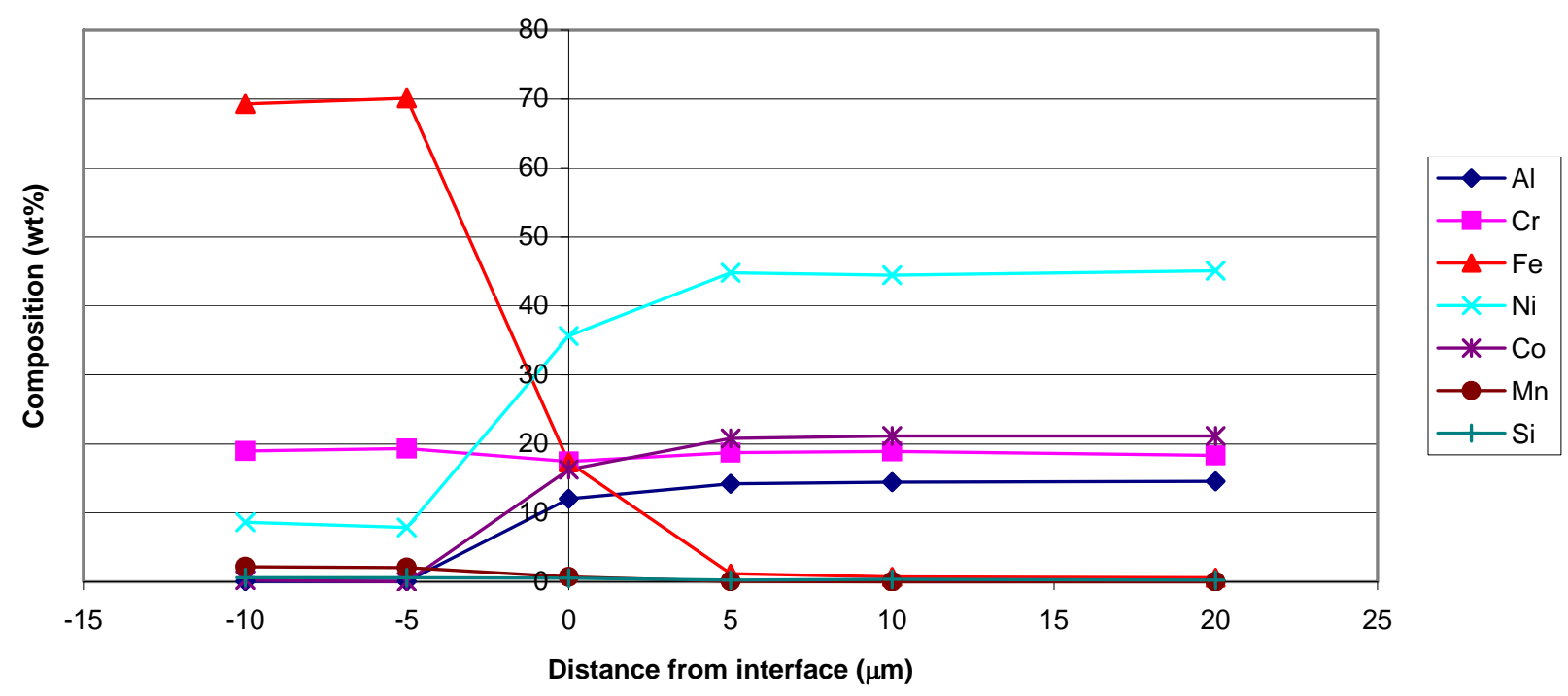

(c) Coating composition profile with base metal on left

Fig. 6. (cont.) As-sprayed HVOF NiCoCrAlY (c) coating composition profile 


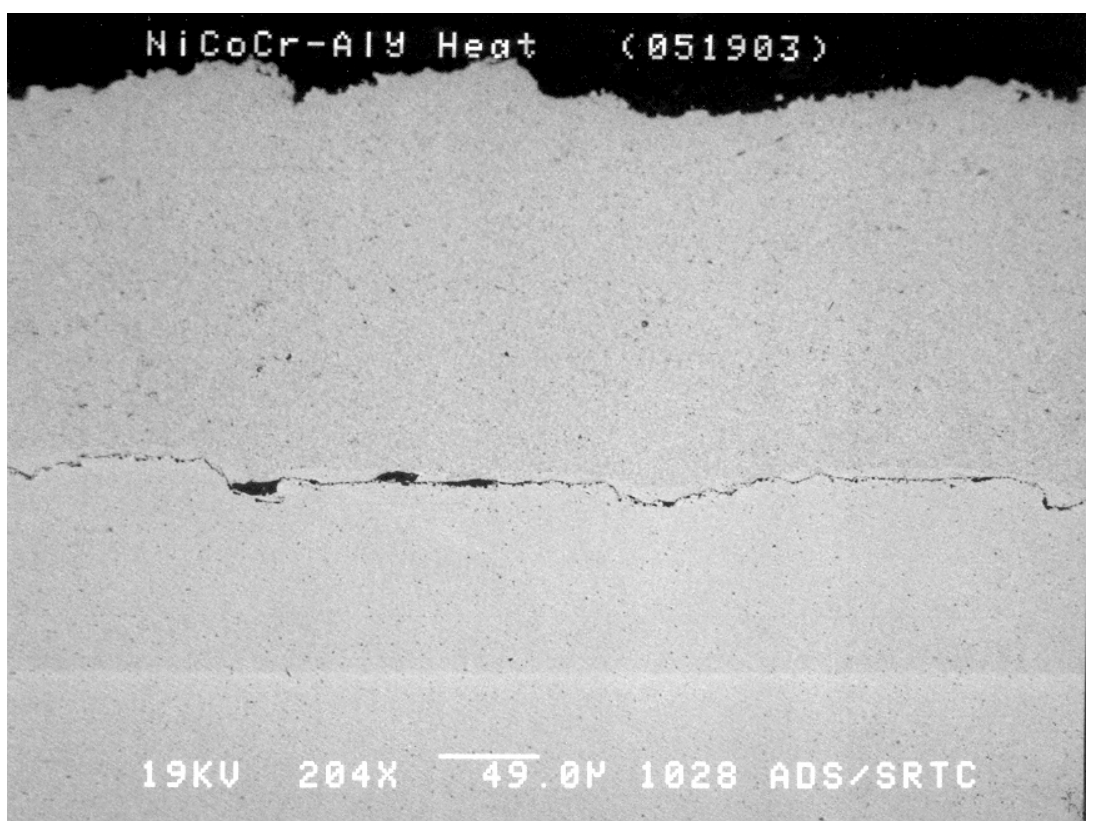

(a) SEM Micrograph of coating

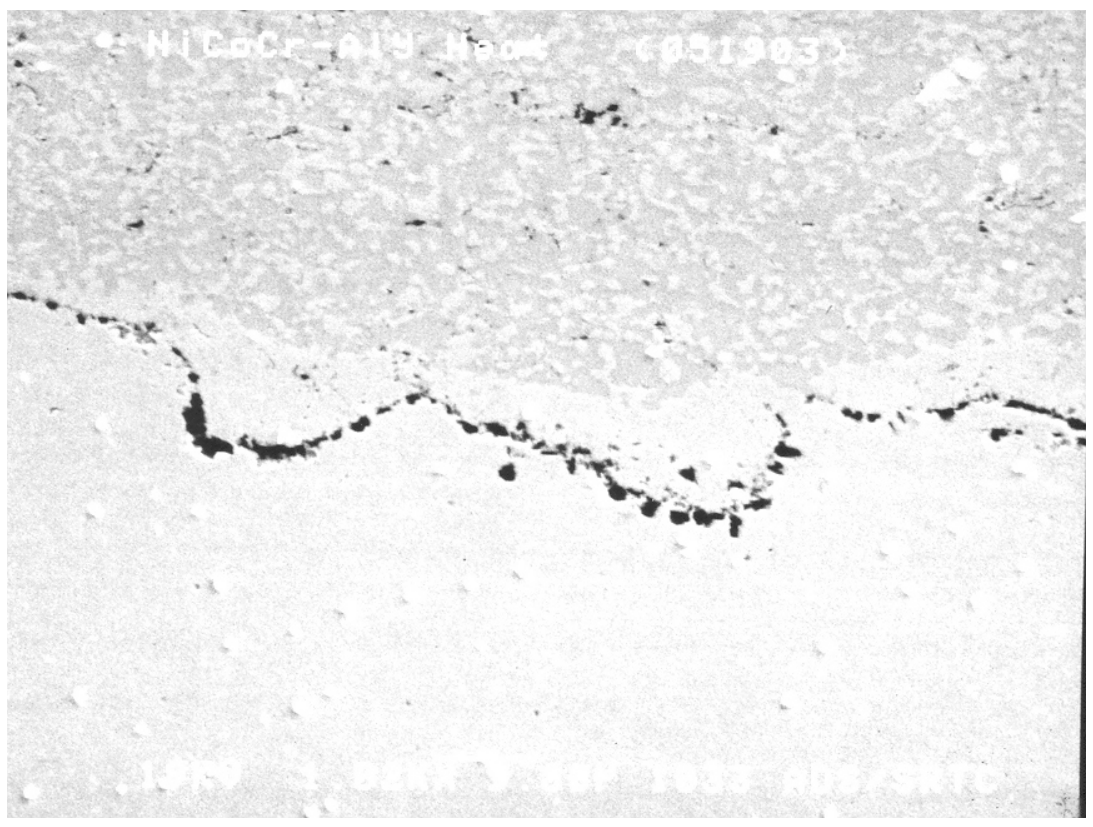

(b) SEM micrograph showing interface

Fig.7. Heat treated HVOF NiCoCrAlY (a) SEM micrograph of coating (b) SEM micrograph near interface (c) typical XEDA spectrum from coating (d) XEDA spectrum from interface (e) coating composition profile with base metal on left. 
ThermoNORAN

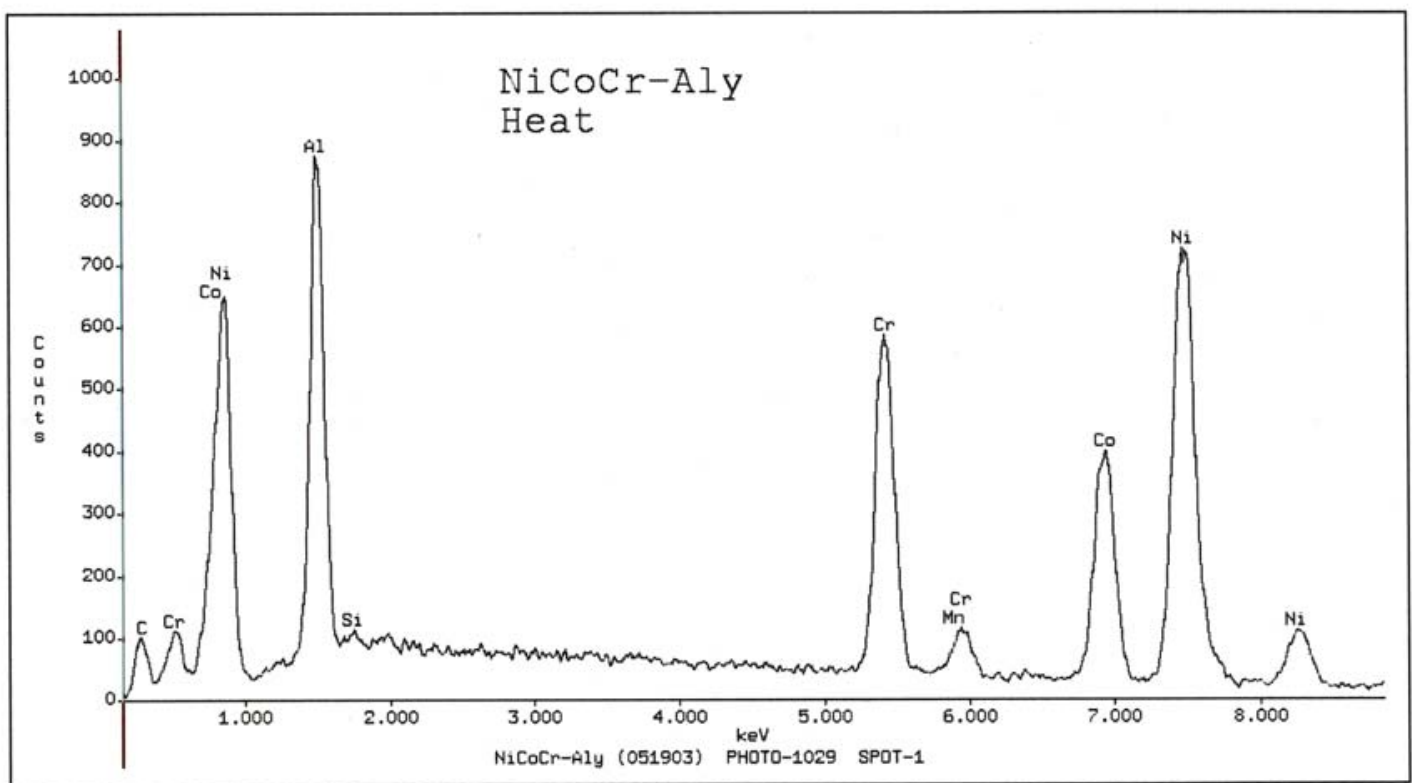

NiCoCr-Aly (051903) PHOTO-1029 SPOT-1

Accelerating Voltage: $19 \mathrm{KeV}$ Take Off Angle: $25.7307^{\circ} \quad$ Live Time: 41.8 seconds Dead Time: 10.563 seconds (c) Typical XEDA spectrum from coating

ThermoNORAN

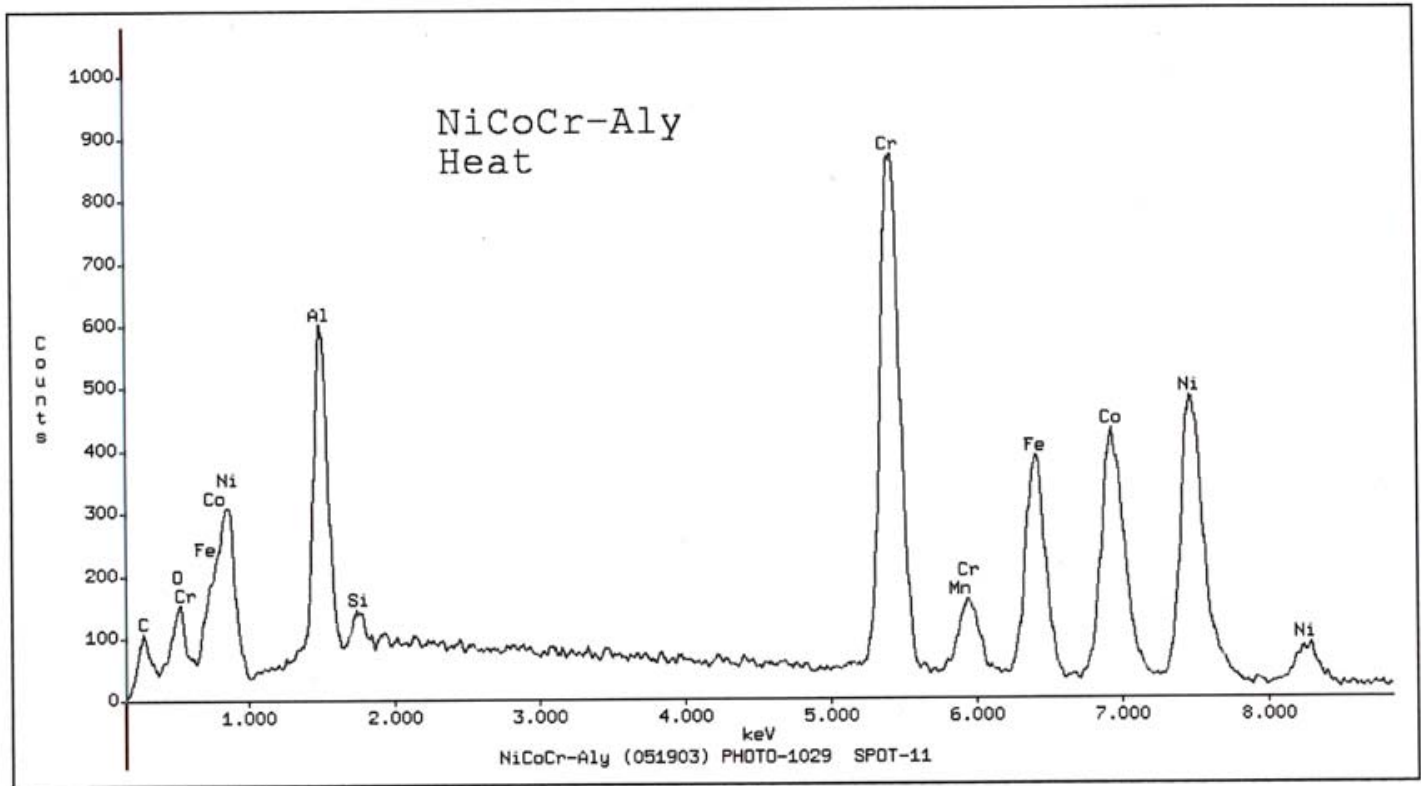

NiCoCr-Aly (051903) PHOTO-1029 SPOT-11

Accelerating Voltage: $19 \mathrm{KeV}$ Take Off Angle: $25.7307^{\circ}$ Live Time: 43.39 seconds Dead Time: 10.719 seconds

(d) XEDA spectrum from interface

Fig.7. (cont.) Heat treated HVOF NiCoCrAlY(c) typical XEDA spectrum from coating (d) XEDA spectrum from interface 


\section{Composition profile of heat treated HVOF NiCoCrAIY}

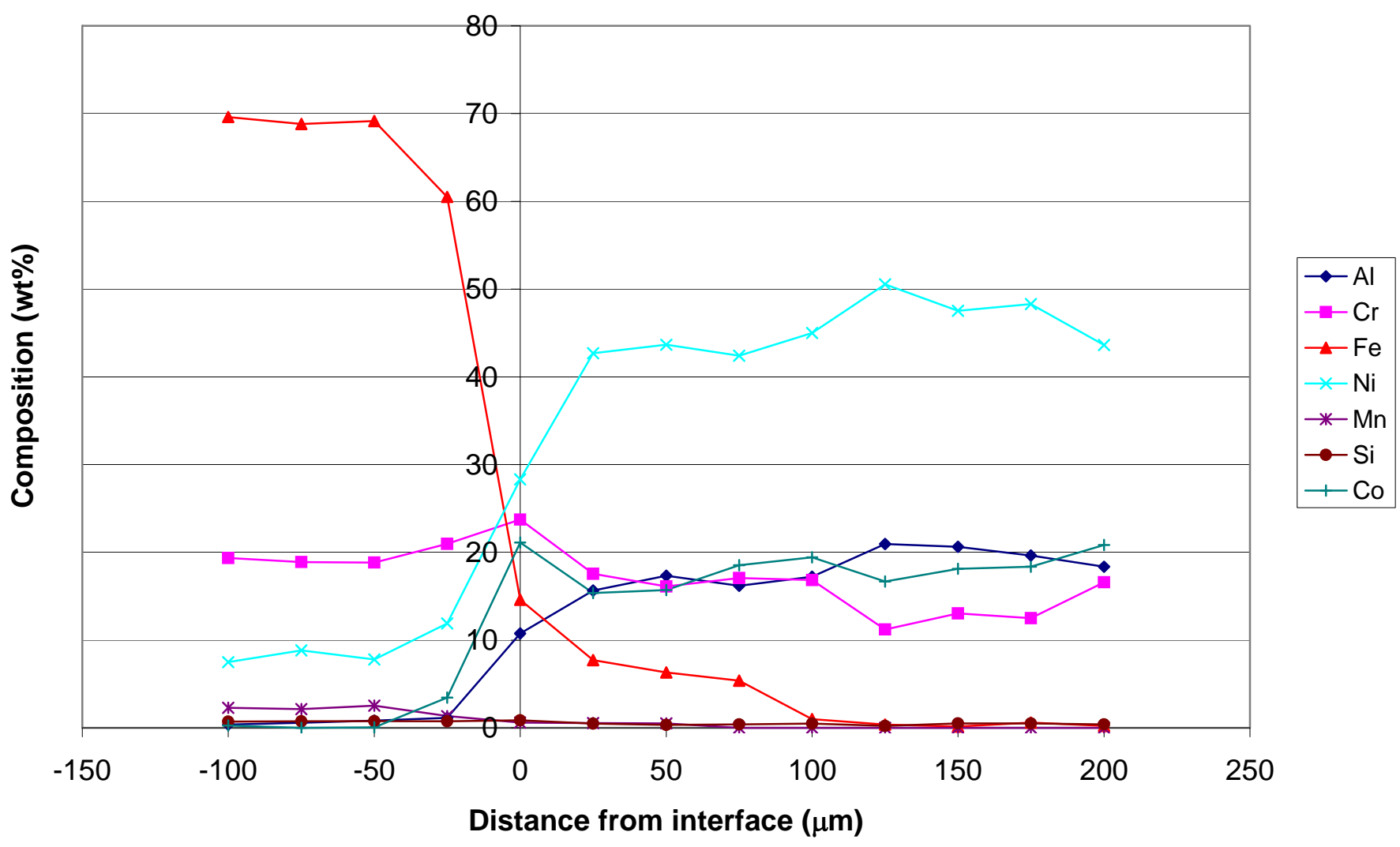

(e) Coating composition profile with base metal on left

Fig.7. (cont.) Heat treated HVOF NiCoCrAlY (e) coating composition profile. 


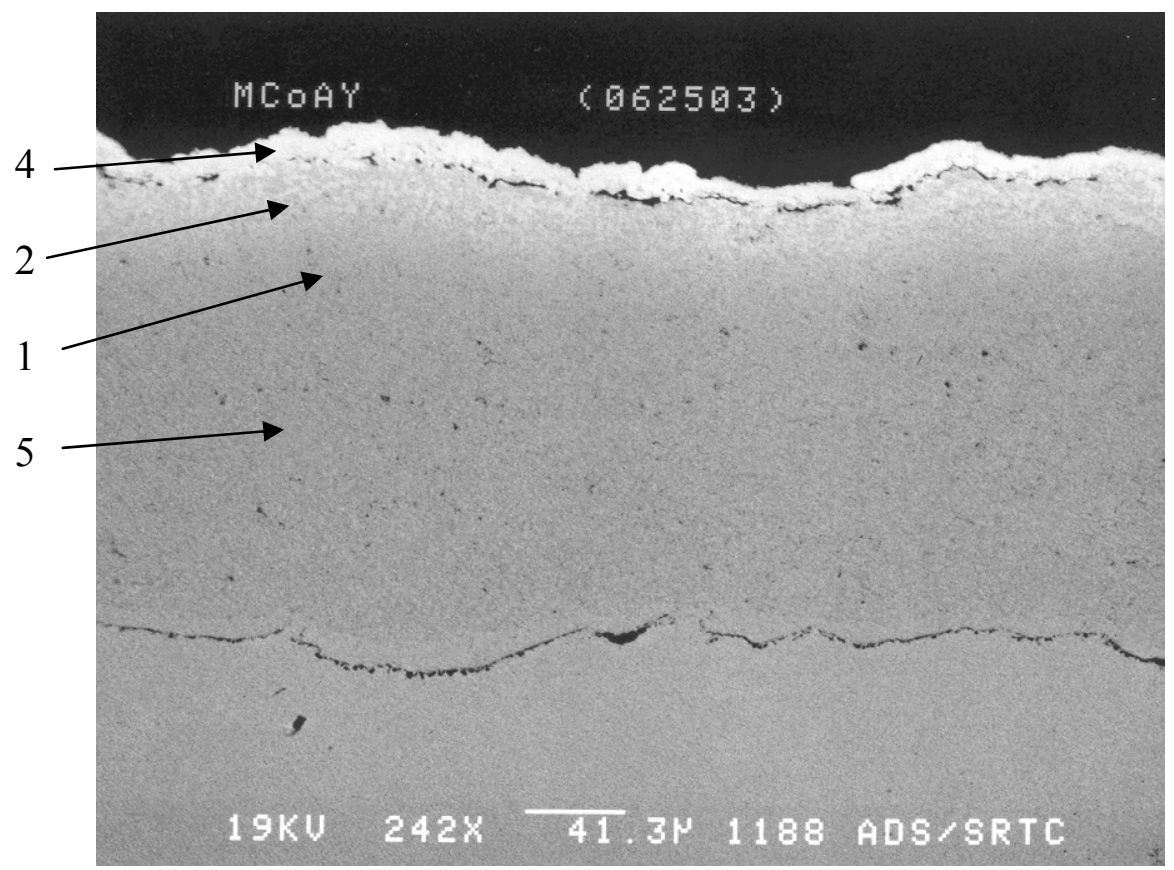

(a) SEM micrograph of overall coating

ThermoNORAN

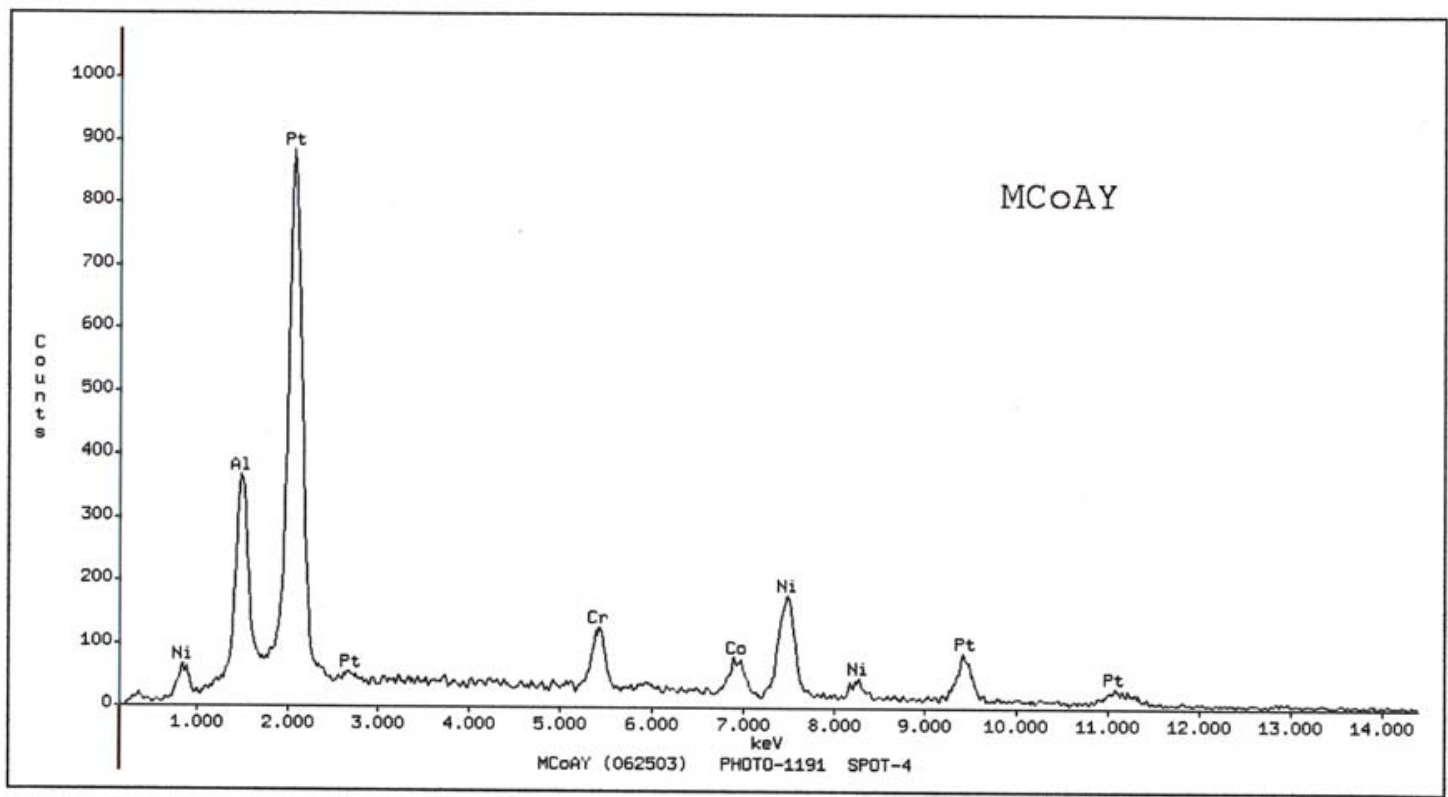

MCoAY (062503) PHOTO-1191 SPOT-4

Accelerating Voltage: $25 \mathrm{KeV}$ Take Off Angle: $10.0806^{\circ}$

Live Time: 17.51 seconds

Dead Time: 2.683 seconds

(b) XEDA spectrum from outer layer of coating spot 4

Fig. 8. Platinized HVOF NiCoCrAlY (a) SEM Micrograph of overall coating (b) XEDA spectrum from outer layer of coating spot 4 (c) XEDA spectrum from Pt interdiffusion later spot 2 (d) XEDA spectrum from Pt interdiffusion later spot 1 (e) XEDA spectrum from unalloyed coating spot 5 
Thermo NORAN

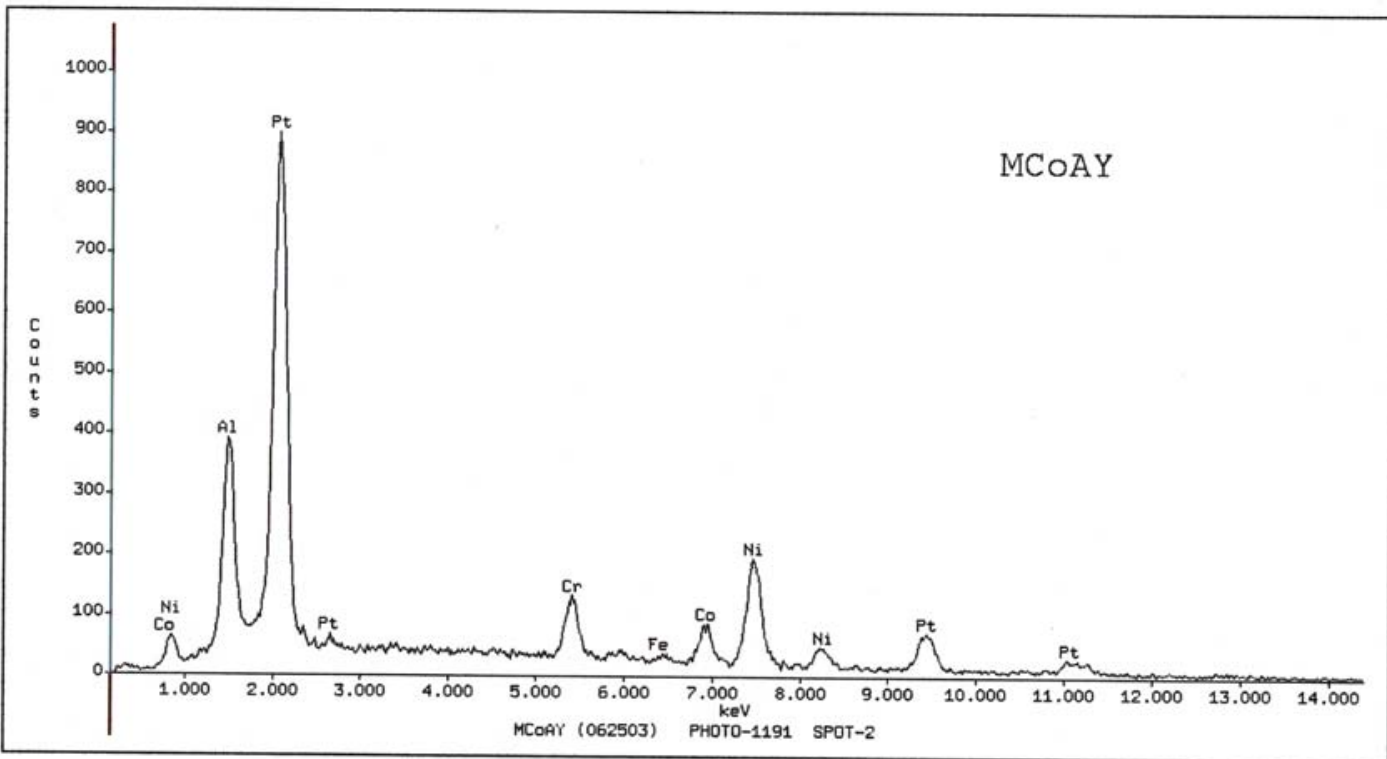

MCoAY (062503) PHOTO-1191 SPOT-2

Accelerating Voltage: $25 \mathrm{KeV}$ Take Off Angle: $10.0806^{\circ}$ Live Time: 54.8 seconds Dead Time: 3.66 seconds

(c) XEDA spectrum from Pt interdiffusion layer spot 2

Thermo NORAN

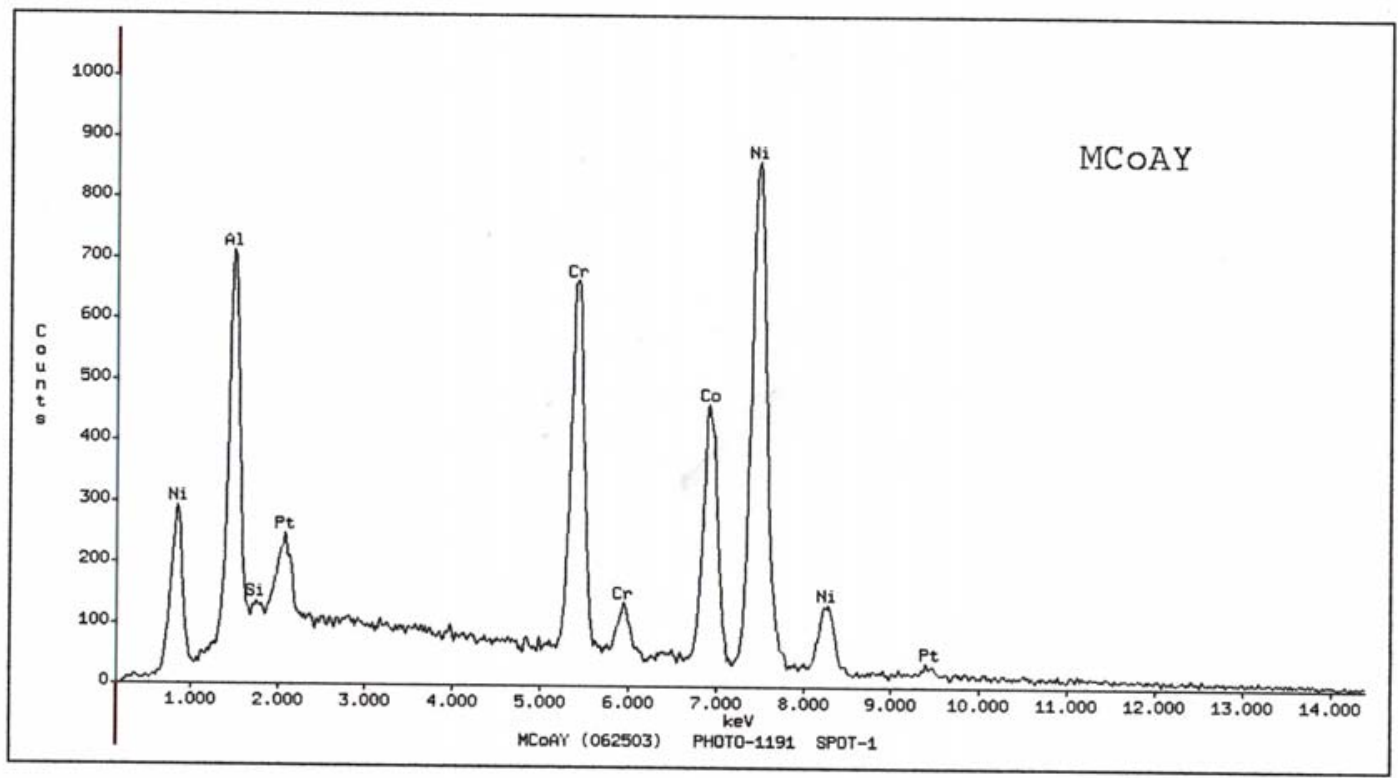

MCoAY (062503) PHOTO-1191 SPOT-1

Accelerating Voltage: $25 \mathrm{KeV}$ Take Off Angle: $10.0806^{\circ} \quad$ Live Time: 81.04 seconds $\quad$ Dead Time: 6.083 seconds

(d) XEDA spectrum from Pt interdiffusion layer spot 1

Fig. 8. (cont.) Platinized HVOF NiCoCrAlY (c) XEDA spectrum from Pt interdiffusion later spot 2 (d) XEDA spectrum from Pt interdiffusion later spot 1 
ThermoNORAN

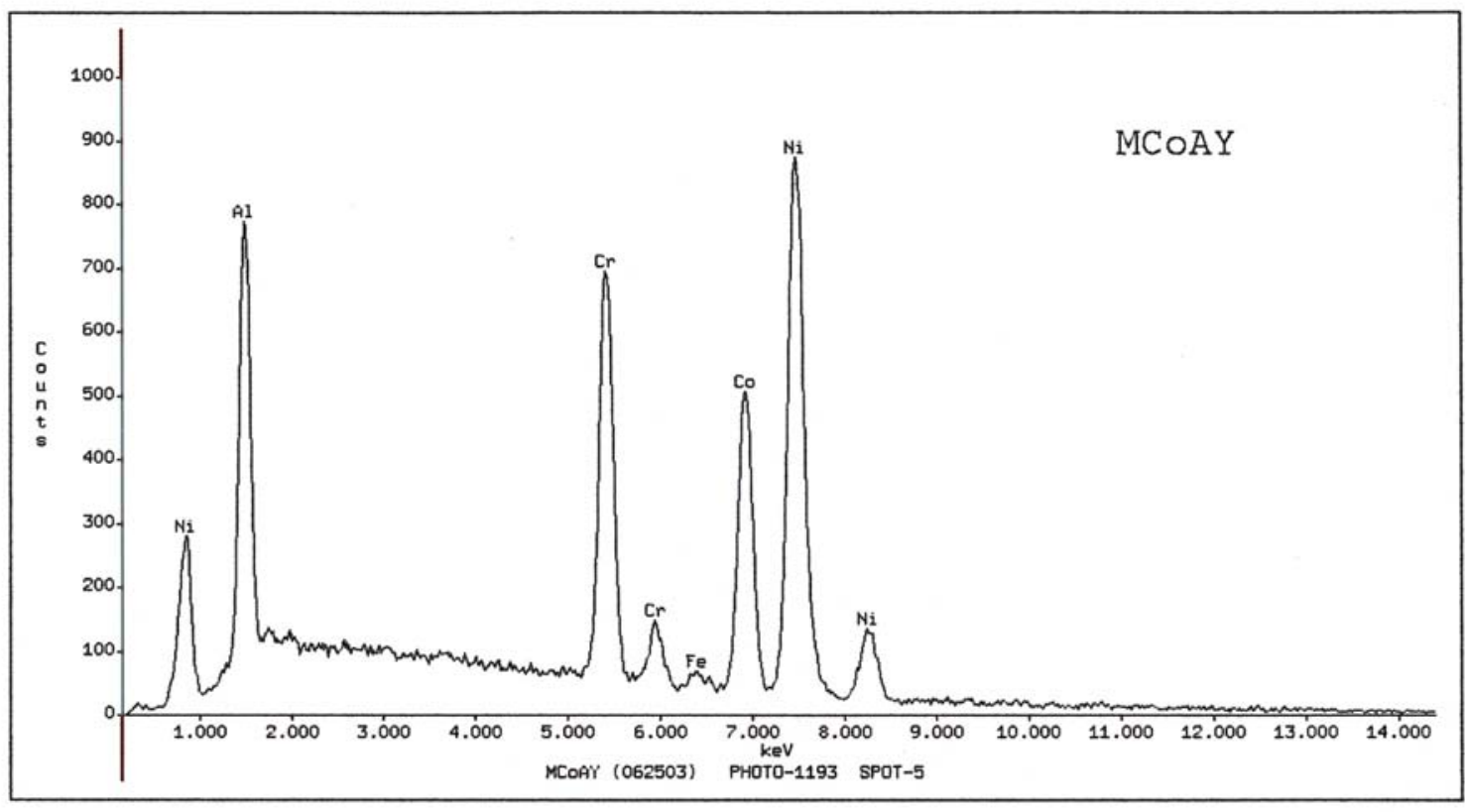

MCoAY (062503) PHOTO-1193 SPOT-5

Accelerating Voltage: $25 \mathrm{KeV}$ Take Off Angle: $10.0806^{\circ}$ Live Time: 48.04 seconds Dead Time: 5.244 seconds

(e) XEDA spectrum from unalloyed coating spot 5

Fig. 8. (cont.) Platinized HVOF NiCoCrAlY (e) XEDA spectrum from unalloyed coating spot 5 


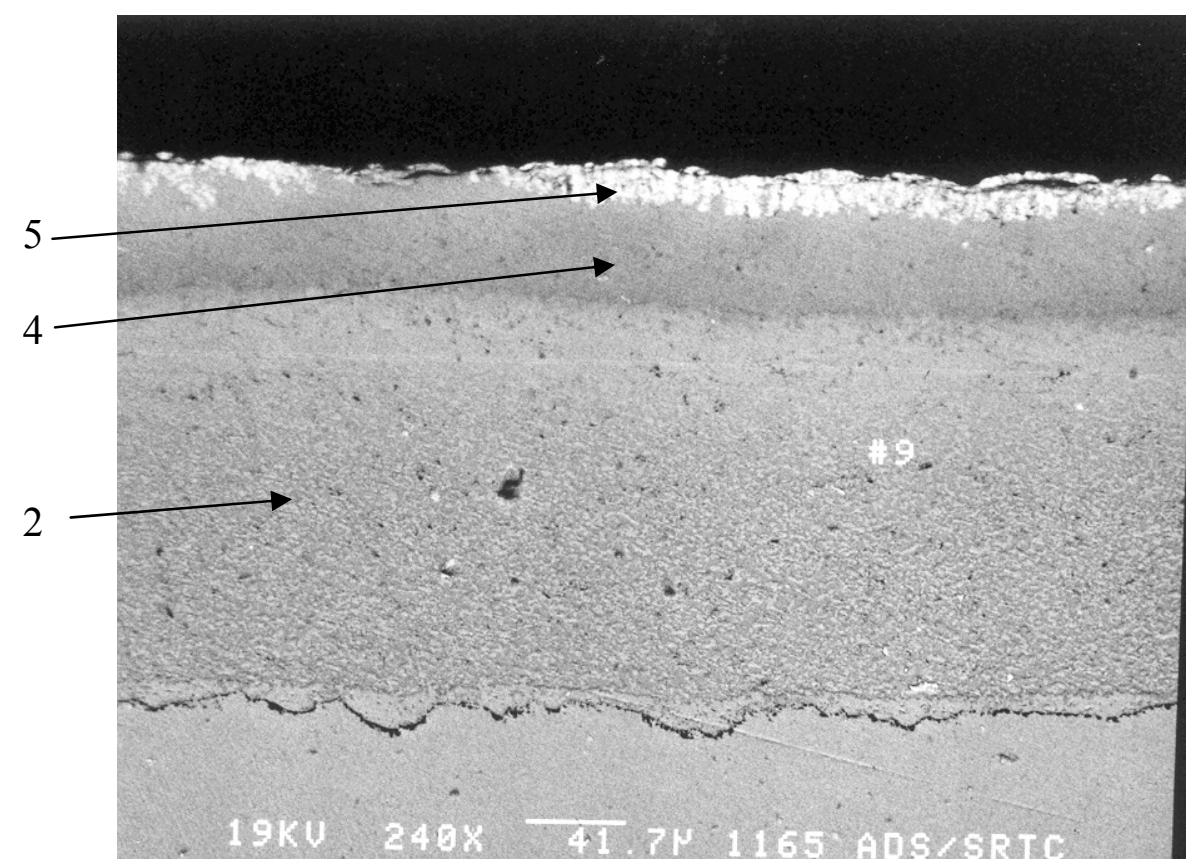

(a) SEM micrograph

ThermoNORAN

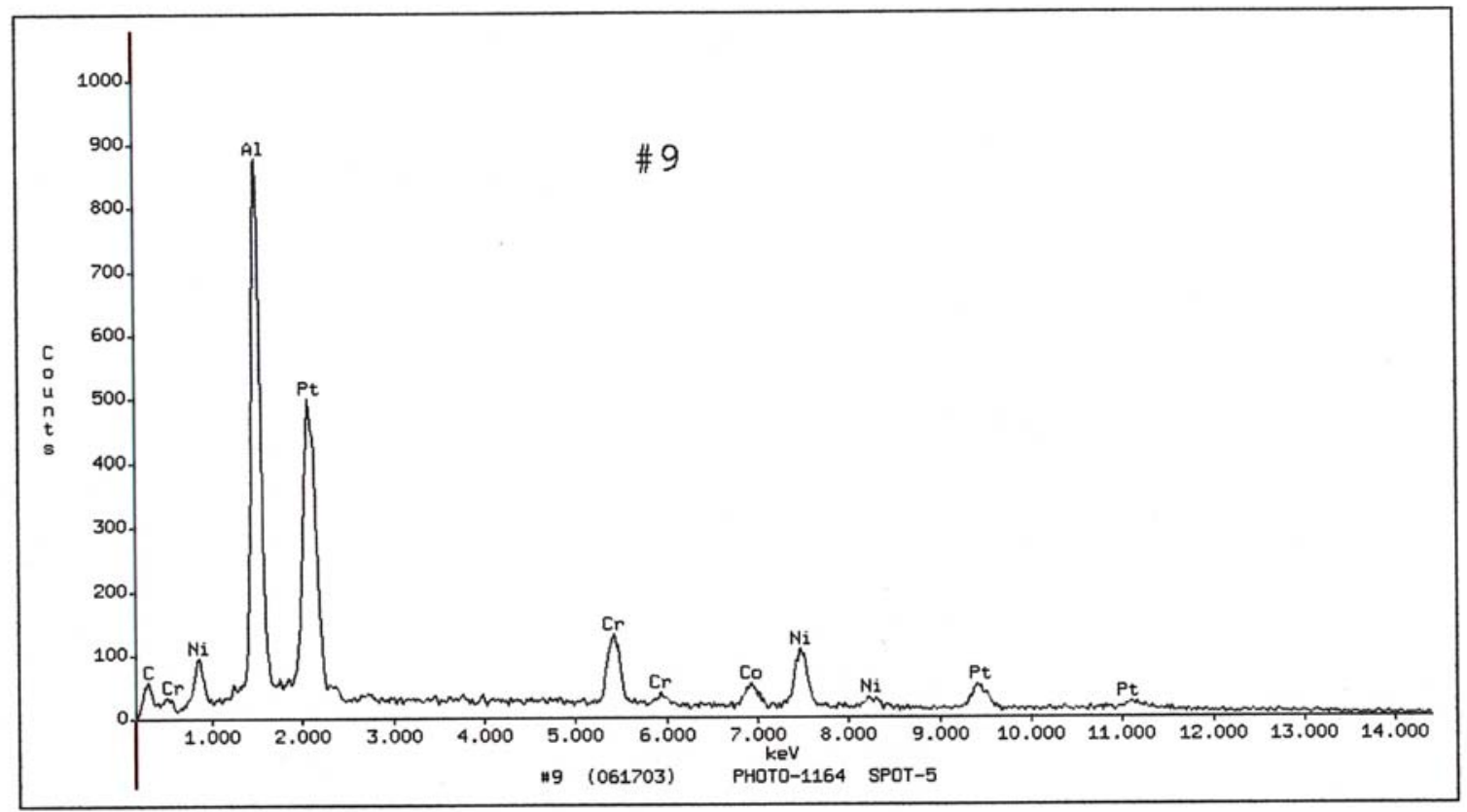

\#9 (061703) PHOTO-1164 SPOT-5

Accelerating Voltage: $10 \mathrm{KeV}$

Take Off Angle: $16.2414^{\circ} \quad$ Live Time: 44.56 seconds

Dead Time: 6.048 seconds

(b) XEDA spectrum of outer coating spot 5

Fig. 9. Platinum aluminized HVOF NiCoCrAlY (a) SEM micrograph (b) XEDA spectrum of outer coating spot 5 (c) XEDA spectrum of interdiffusion zone spot 4 (d) XEDA spectrum of unalloyed coating spot 2 . 
ThermoNORAN

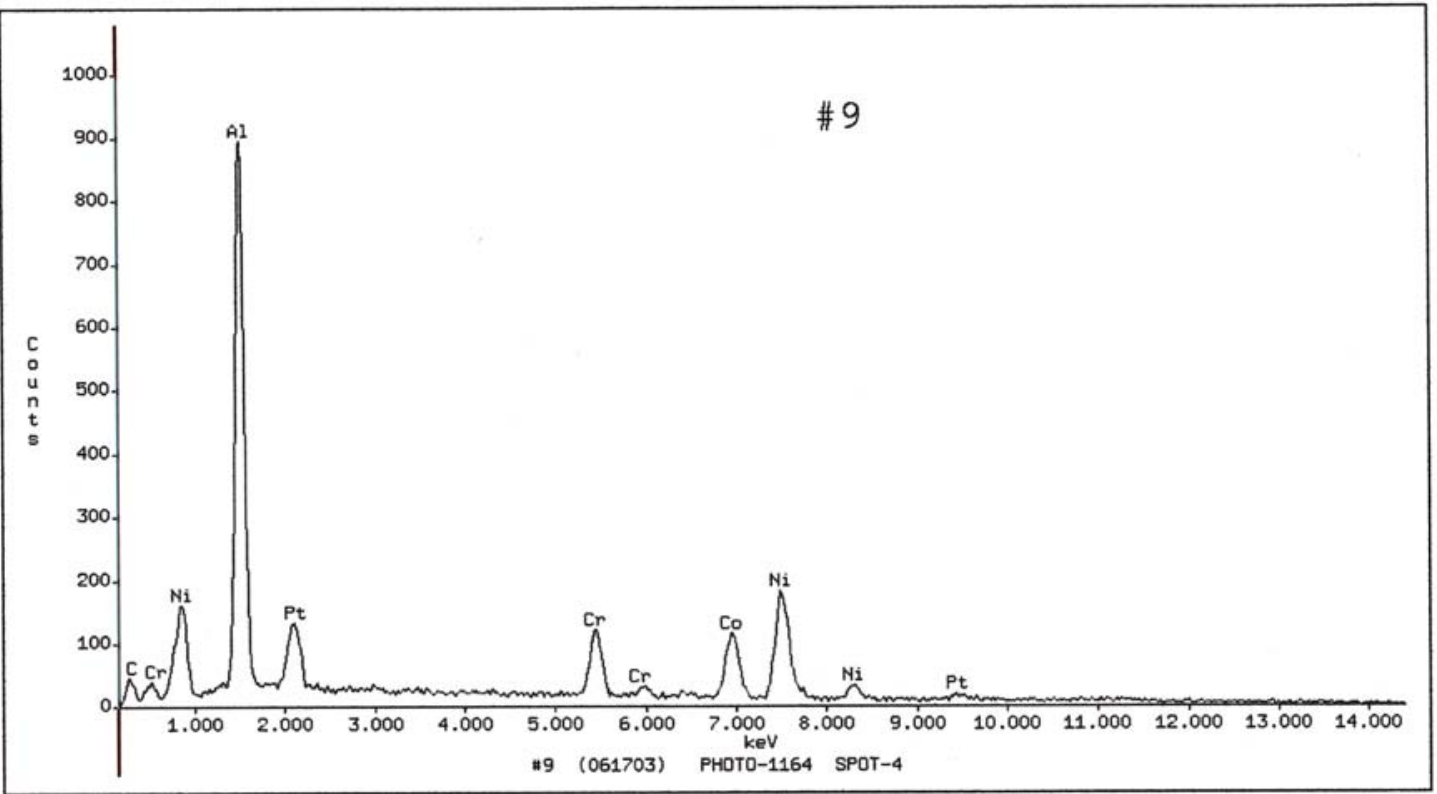

\#9 (061703) PHOTO-1164 SPOT-4

Accelerating Voltage: $25 \mathrm{KeV}$ Take Off Angle: $10.0806^{\circ}$ Live Time: 54.16 seconds Dead Time: 5.11 seconds

(c) XEDA spectrum of interdiffusion zone spot 4

Thermo NORAN

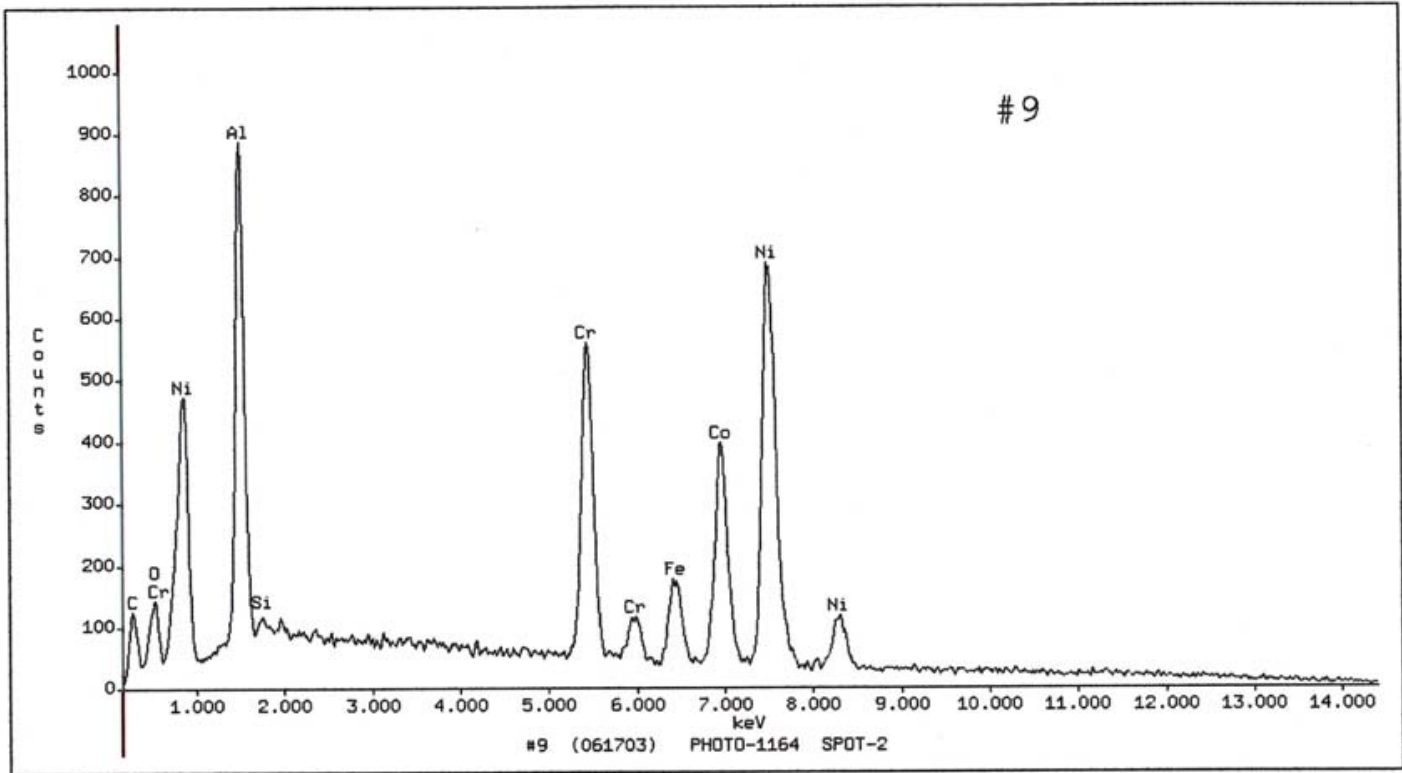

\#9 (061703) PHOTO-1164 SPOT-2

Accelerating Voltage: $25 \mathrm{KeV}$ Take Off Angle: $10.0806^{\circ}$ Live Time: 53.84 seconds Dead Time: 11.404 seconds

(d) XEDA spectrum of unalloyed coating spot 2

Fig. 9. (cont.) Platinum aluminized HVOF NiCoCrAlY (c) XEDA spectrum of interdiffusion zone spot 4 (d) XEDA spectrum of unalloyed coating spot 2. 


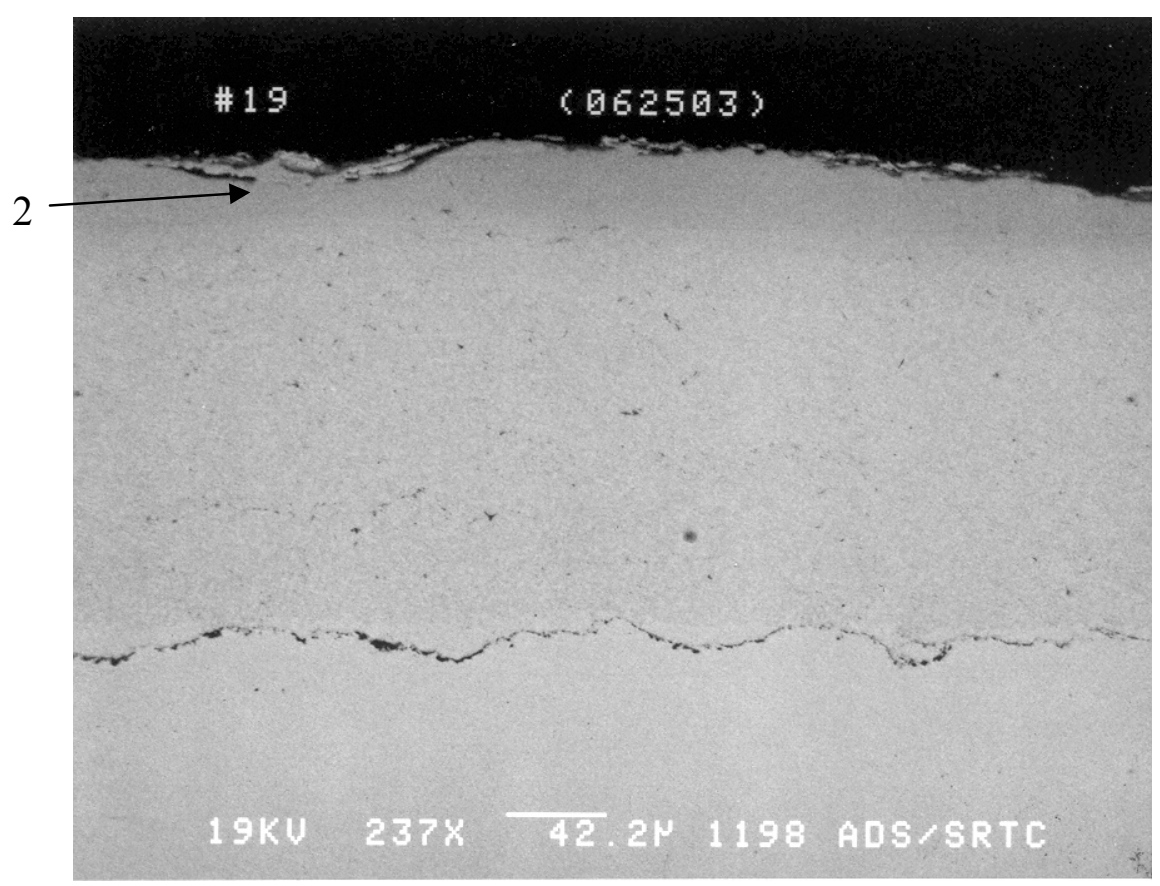

(a) SEM micrograph

ThermoNORAN

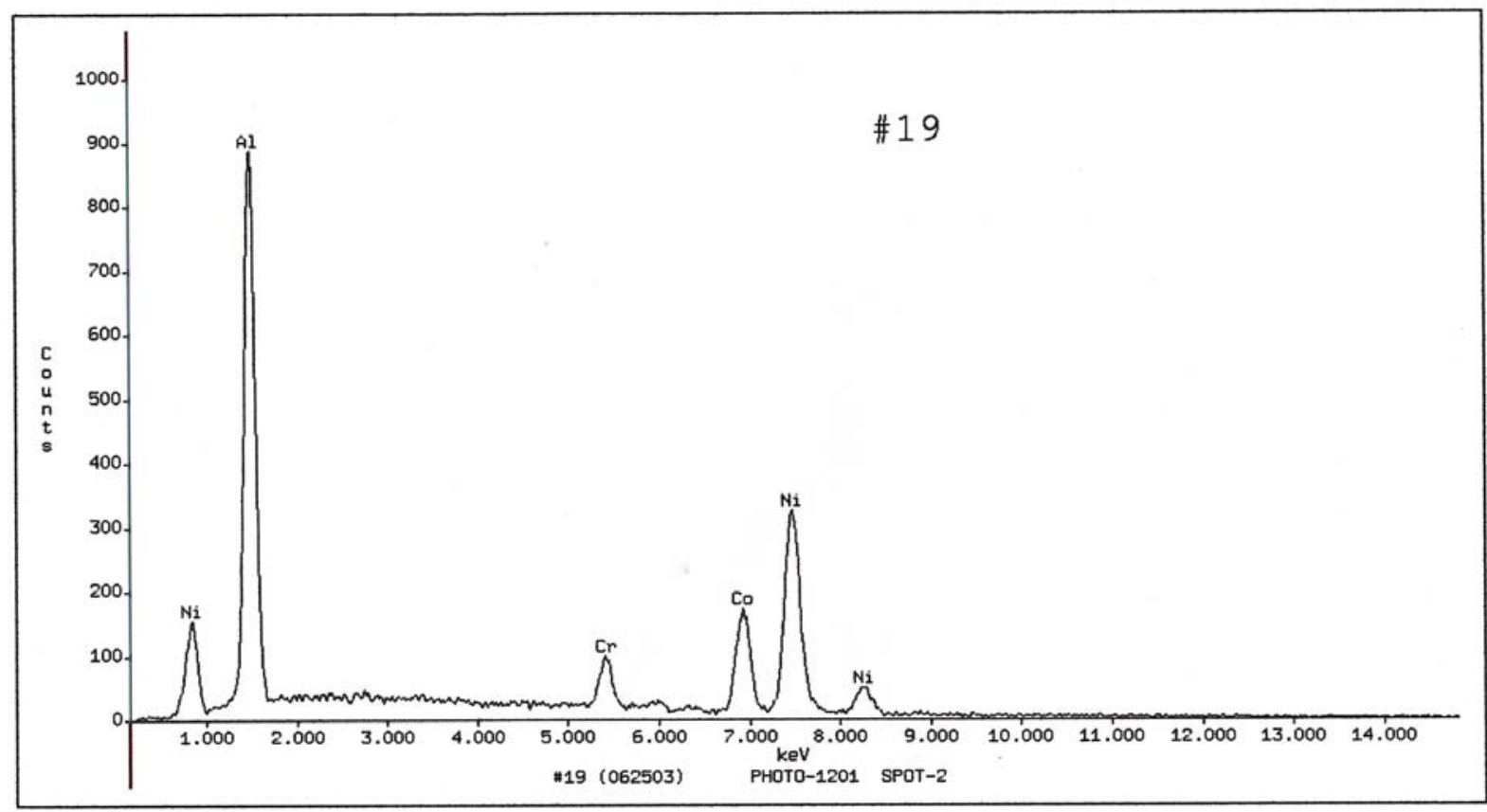

\#19 (062503) PHOTO-1201 SPOT-2

Accelerating Voltage: $25 \mathrm{KeV}$

Take Off Angle: $10.0806^{\circ}$

Live Time: 22.41 seconds

Dead Time: 2.1 seconds

(b) XEDA spectrum from outer layer spot 2

Fig. 10. Aluminized HVOF NiCoCrAlY (a) SEM micrograph (b) XEDA spectrum from outer layer spot 3 (c) SEM micrograph of unaffected area (d) XEDA spectrum from unaffected area spot 4, dark gray (e) XEDA spectrum from unaffected area spot 5, light gray 


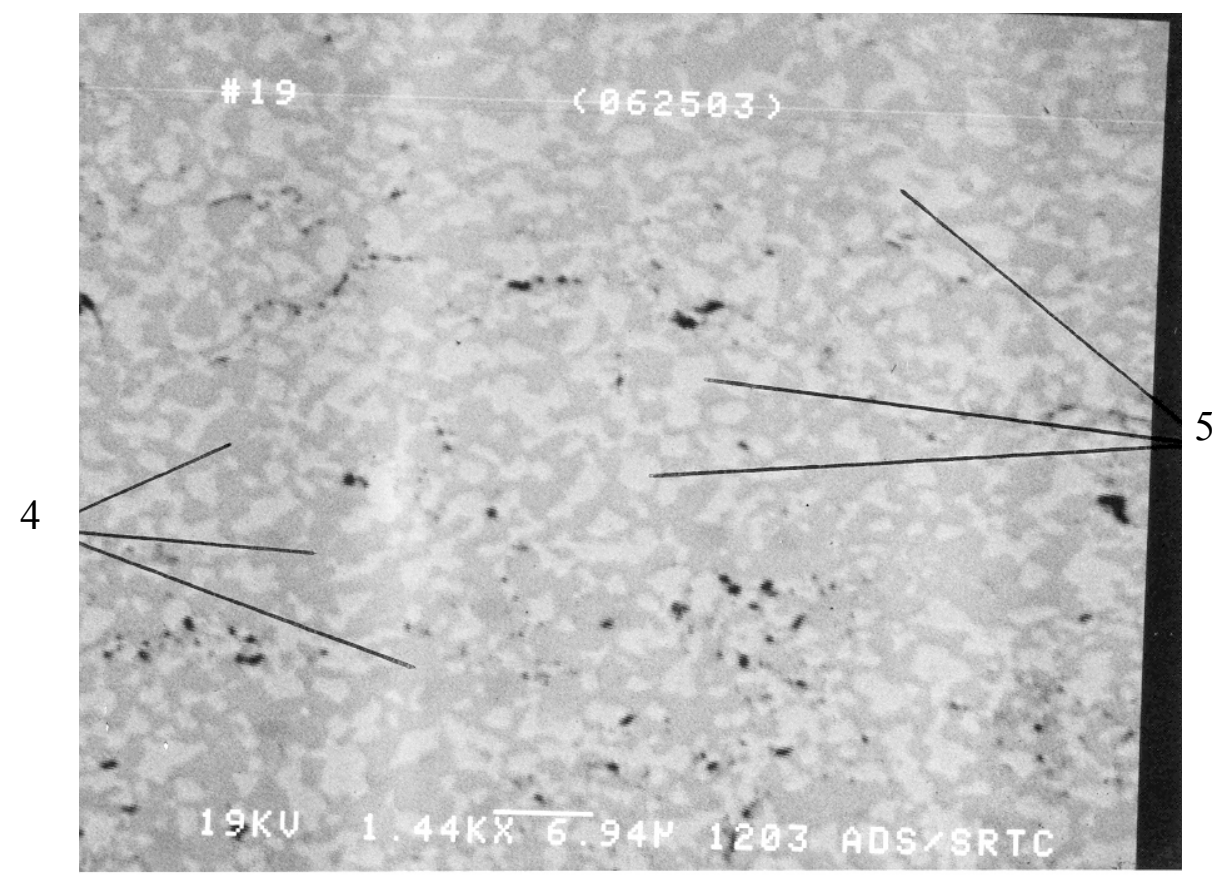

(c) SEM micrograph of unaffected area

ThermoNORAN

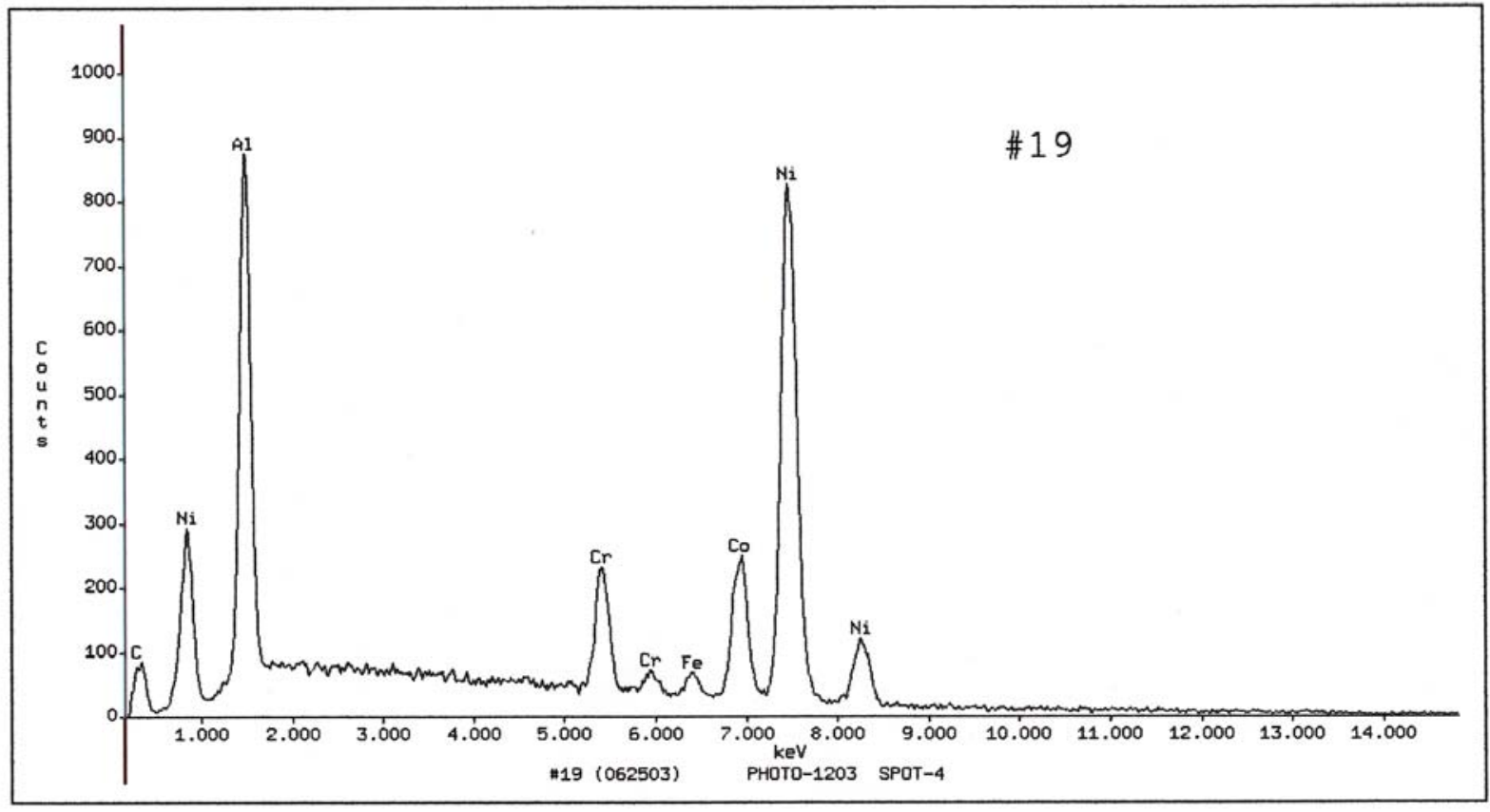

\#19 (062503) PHOTO-1203 SPOT-4

Accelerating Voltage: $25 \mathrm{KeV}$ Take Off Angle: $10.0806^{\circ}$ Live Time: 41.82 seconds Dead Time: 4.778 seconds

(d) XEDA spectrum from unaffected area spot 4, dark gray

Fig. 10. (cont.) Aluminized HVOF NiCoCrAlY (c) SEM micrograph of unaffected area (d) XEDA spectrum from unaffected area spot 4 , dark gray 
ThermoNORAN

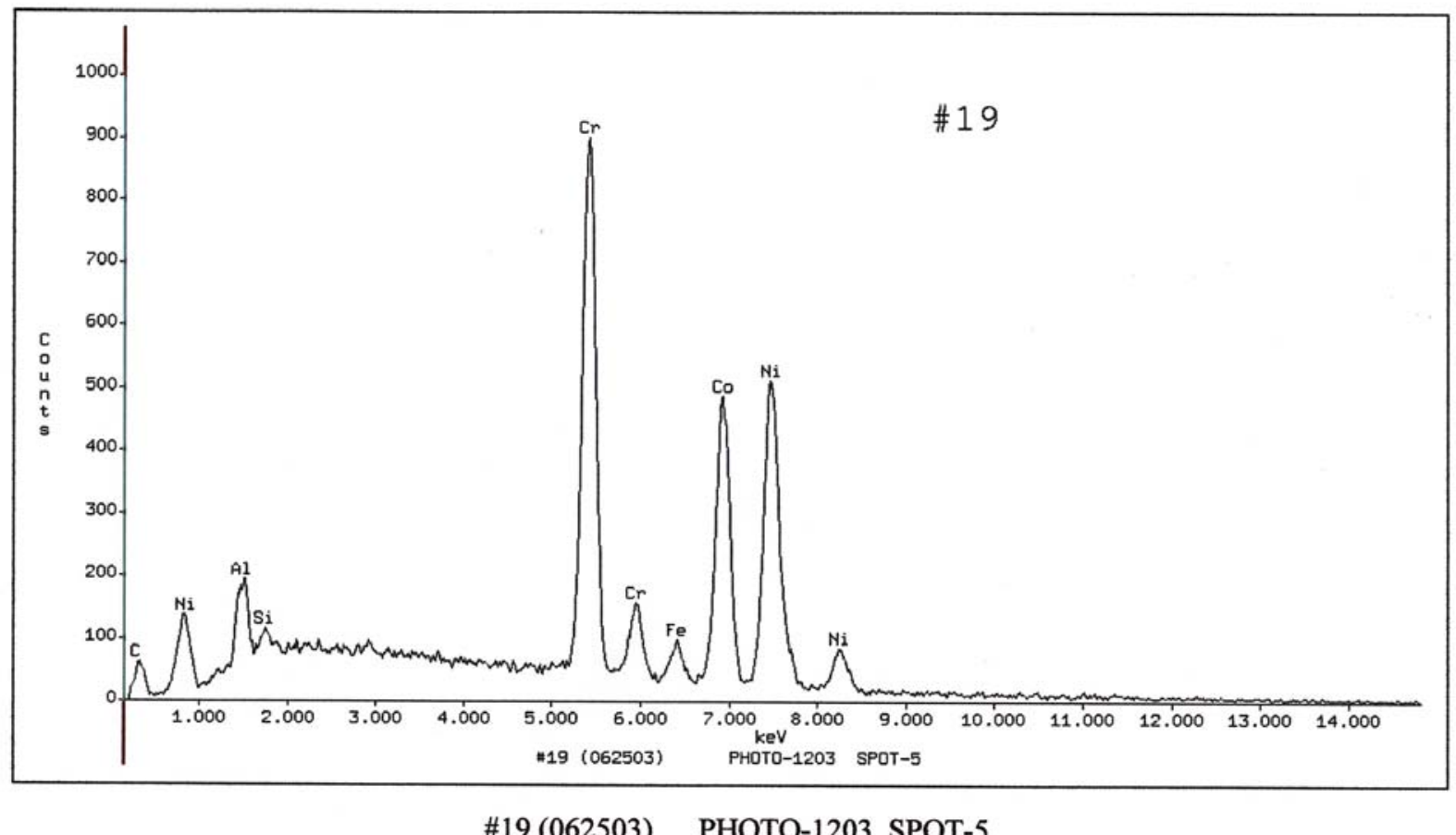

PHOTO-1203 SPOT-5

Accelerating Voltage: $25 \mathrm{KeV}$ Take Off Angle: $10.0806^{\circ} \quad$ Live Time: 40.45 seconds $\quad$ Dead Time: 4.344 seconds

(e) XEDA spectrum from unaffected area spot 5, light gray

Fig. 10. (cont.) Aluminized HVOF NiCoCrAlY (e) XEDA spectrum from unaffected area spot 5, light gray 


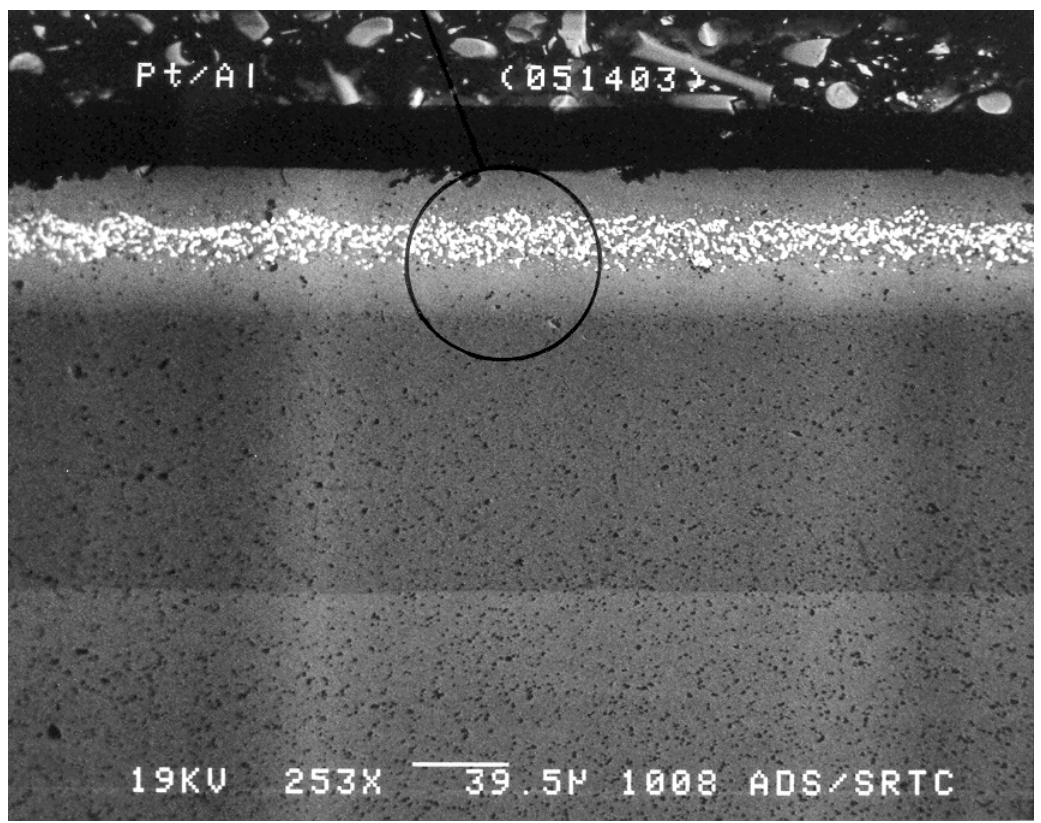

(a) SEM micrograph

ThermoNORAN

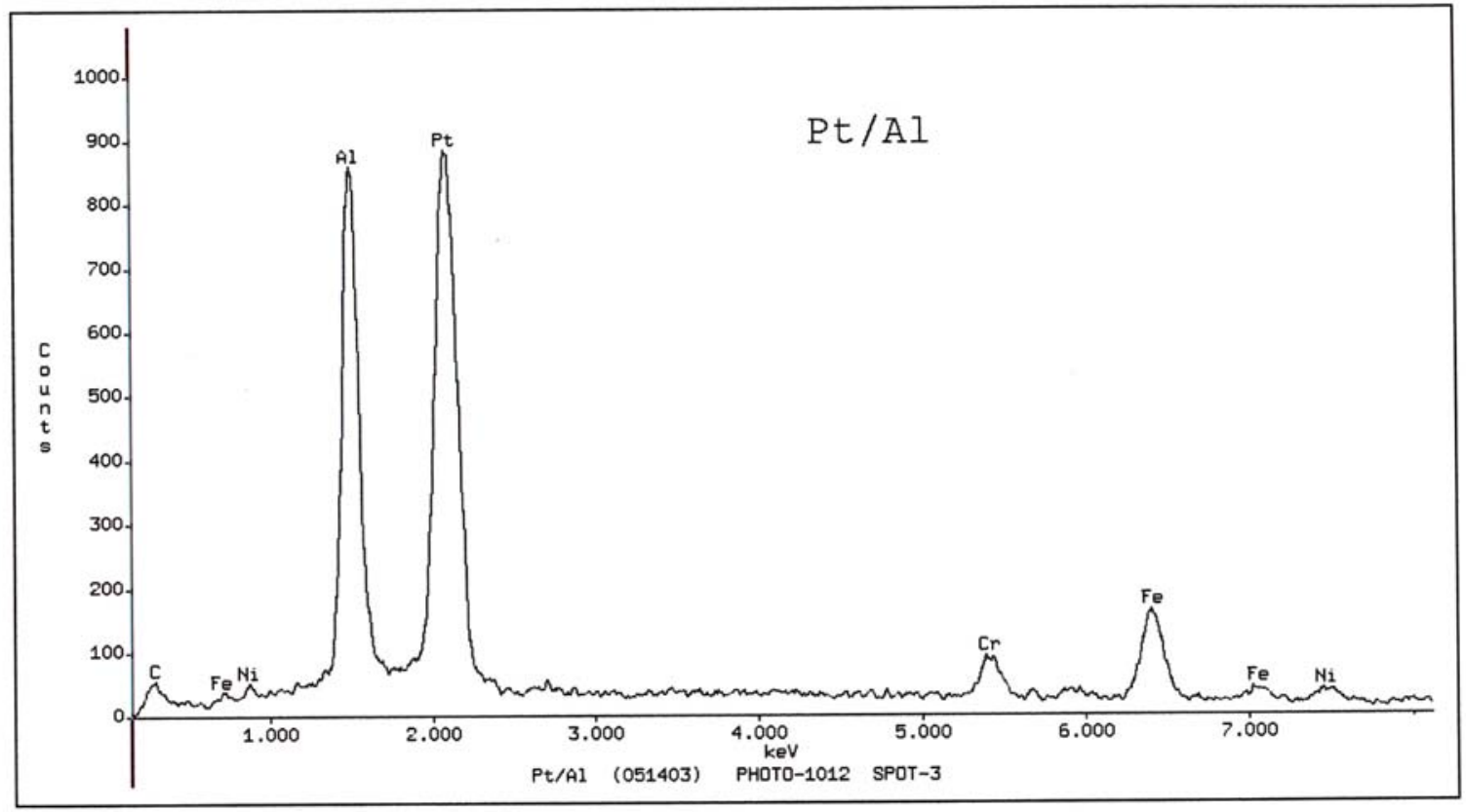

Pt/Al (051403) PHOTO-1012 SPOT-3

Accelerating Voltage: $19 \mathrm{KeV}$ Take Off Angle: $25.7307^{\circ}$ Live Time: 18.16 seconds Dead Time: 6.841 seconds

(b) XEDA spectrum of Pt-rich phase

Fig. 11. Platinum aluminide coated 316 SS (a) SEM micrograph (b) XEDA spectrum of Pt-rich phase (c) XEDA spectrum of matrix in Pt-rich zone (d) XEDA spectrum from the interdiffusion zone (e) XEDA spectrum from interdiffusion layer (f) XEDA spectrum from interdiffusion layer (g) coating composition profile with base metal on left. 
Thermo NORAN

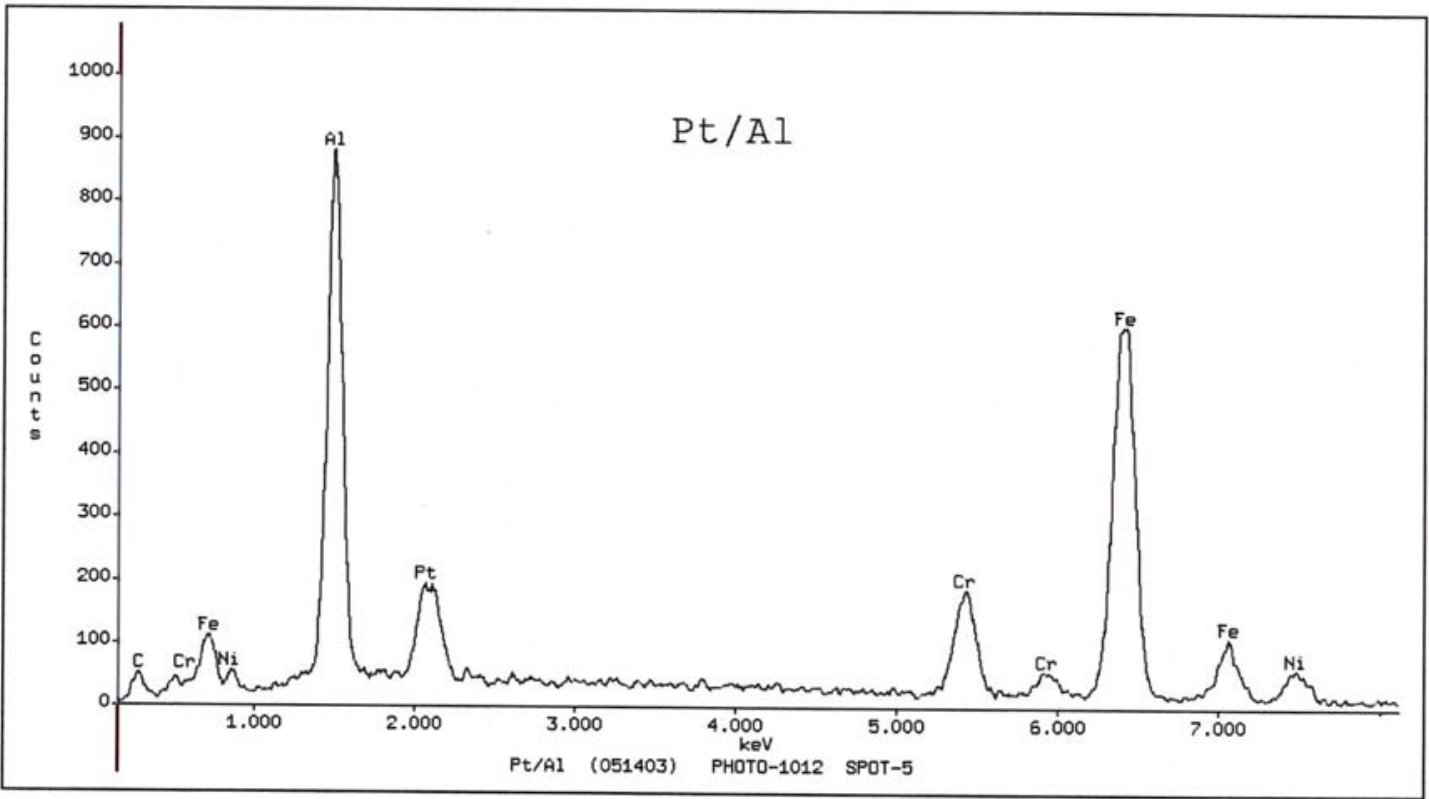

Pt/Al (051403) PHOTO-1012 SPOT-5

Accelerating Voltage: $19 \mathrm{KeV}$ Take Off Angle: $25.7307^{\circ} \quad$ Live Time: 23.04 seconds Dead Time: 6.08 seconds

(c) XEDA spectrum of matrix in Pt-rich zone

ThermoNORAN

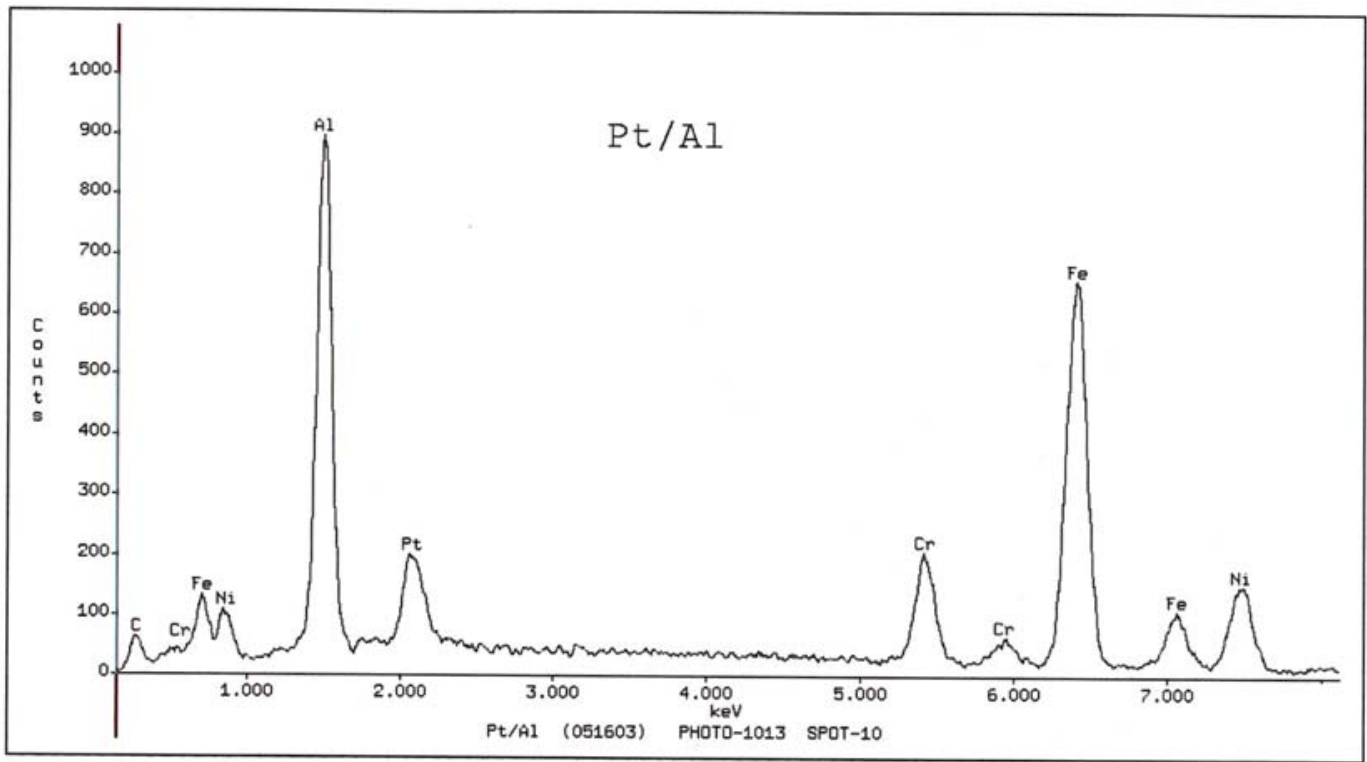

Pt/Al (051603) PHOTO-1013 SPOT-10

Accelerating Voltage: $19 \mathrm{KeV}$ Take Off Angle: $25.7307^{\circ} \quad$ Live Time: 26.54 seconds Dead Time: 6.739 seconds

(d) XEDA spectrum from the interdiffusion zone

Fig. 11. (cont.) Platinum aluminide coated 316 SS (c) XEDA spectrum of matrix in Pt-rich zone (d) XEDA spectrum from the interdiffusion zone 
Thermo NORAN

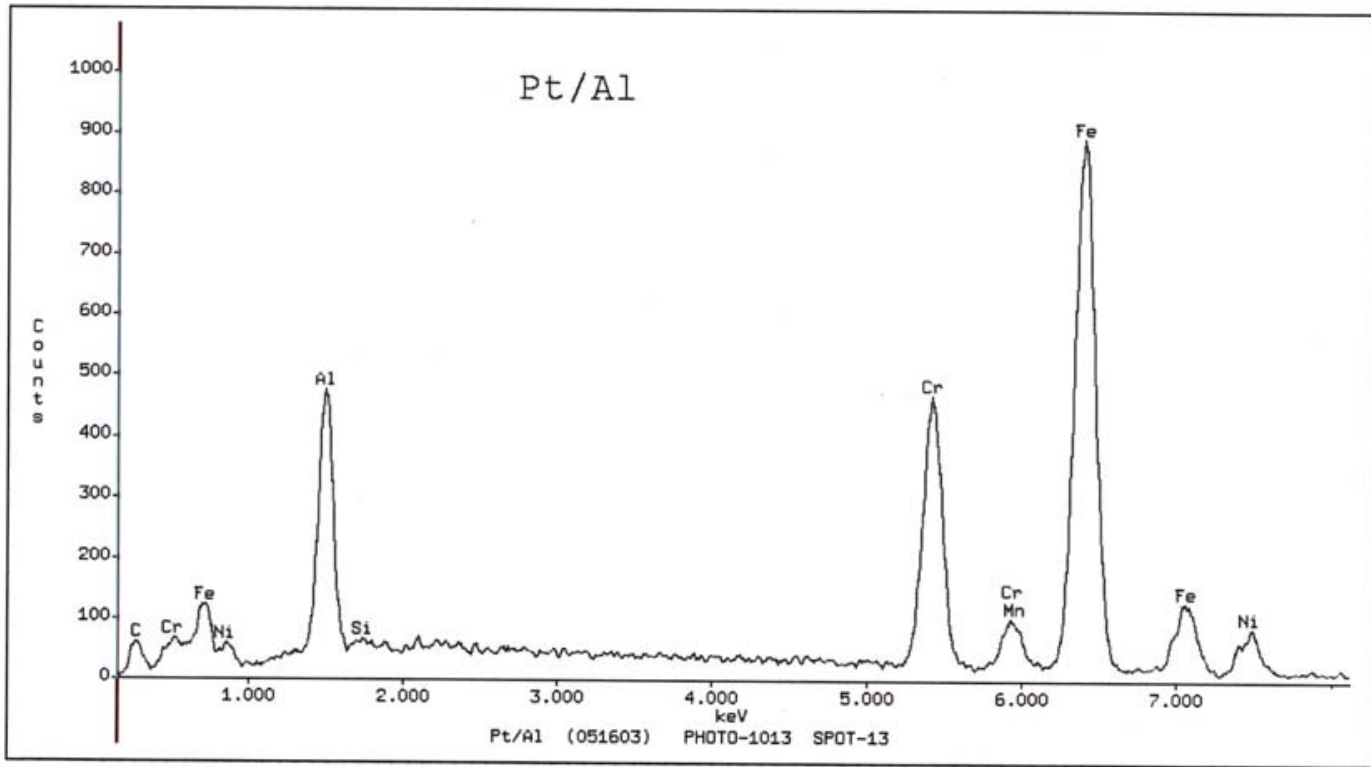

Pt/Al (051603) PHOTO-1013 SPOT-13

Accelerating Voltage: $19 \mathrm{KeV}$ Take Off Angle: $25.7307^{\circ} \quad$ Live Time: 27.54 seconds Dead Time: 6.575 seconds

(e) XEDA spectrum from interdiffusion layer

Thermo NORAN

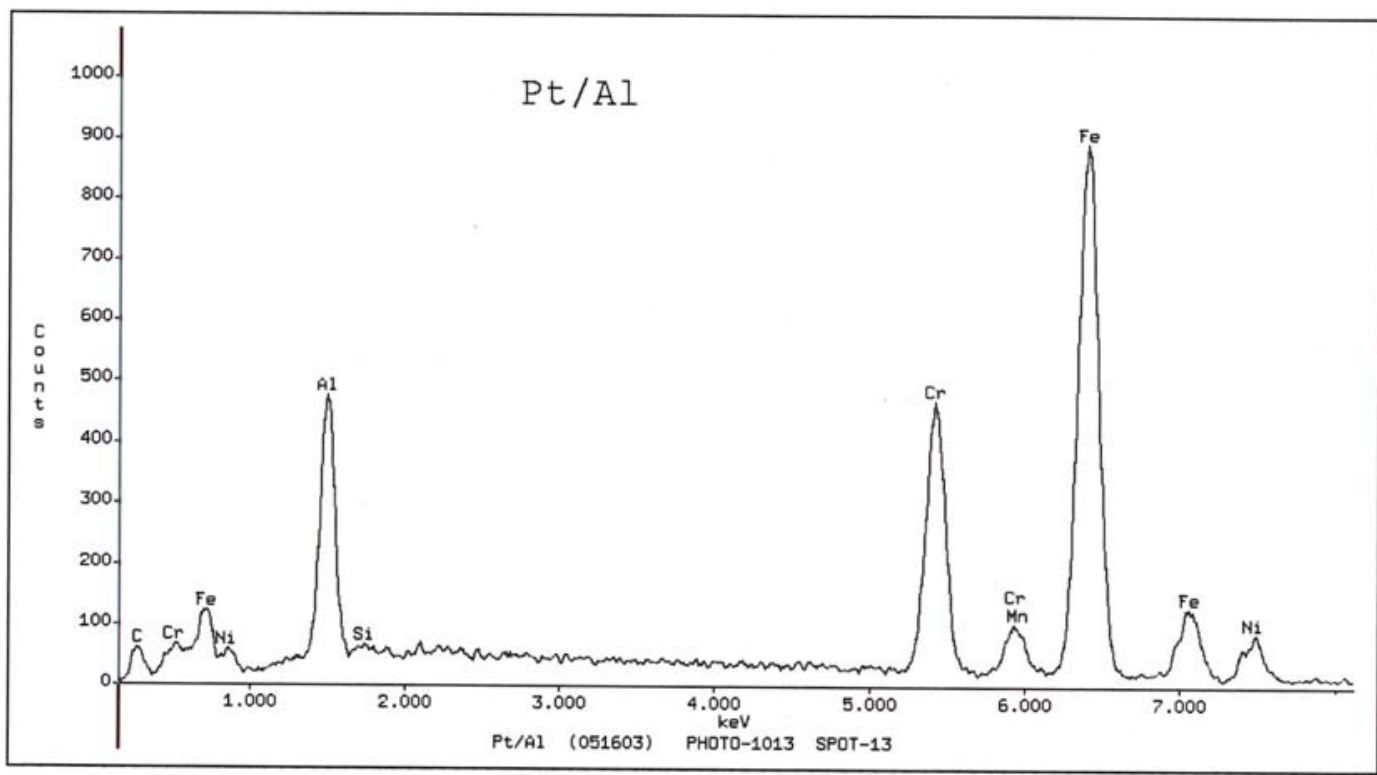

Pt/Al (051603) PHOTO-1013 SPOT-13

Accelerating Voltage: $19 \mathrm{KeV}$

Take Off Angle: $25.7307^{\circ} \quad$ Live Time: 27.54 seconds

Dead Time: 6.575 seconds

(f) XEDA spectrum from interdiffusion layer

Fig. 11. (cont.) Platinum aluminide coated 316 SS (e) XEDA spectrum from interdiffusion layer (f) XEDA spectrum from interdiffusion layer 


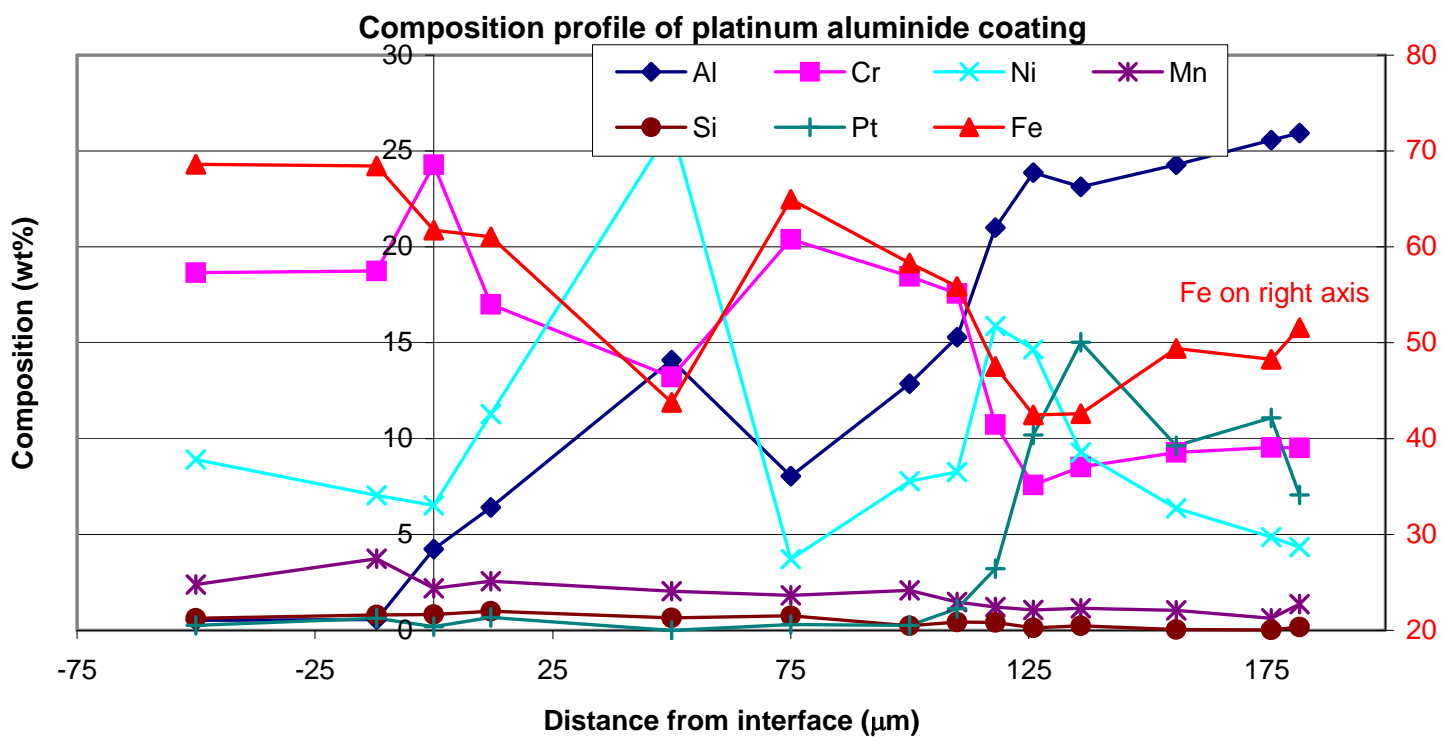

(g) coating composition profile with base metal on left

Fig. 11. (cont.) Platinum aluminide coated 316 SS (g) coating composition profile with basemetal on left. 

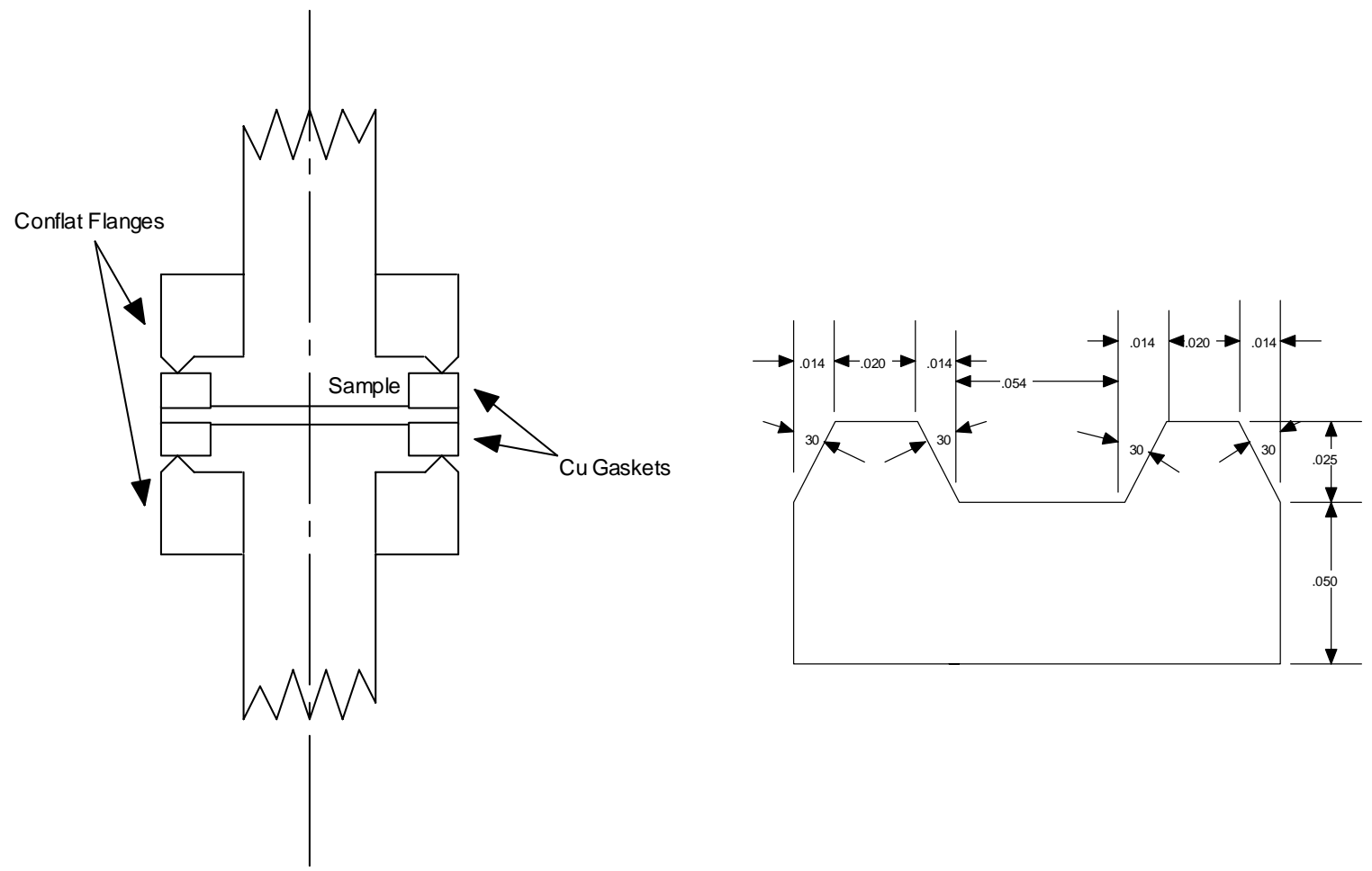

(a) schematic of sample fixture

(b) schematic of machined gasket

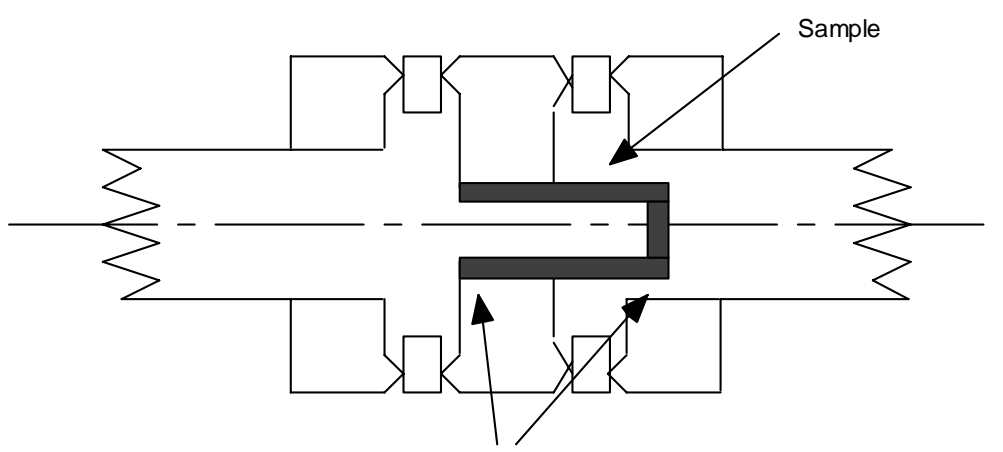

Welds

(c) schematic of next generation sample for testing

Fig. 12. Variations used to improve the seal of the coated samples for testing. (a) schematic of sample loading using copper gaskets (b) schematic of machined gaskets (c) schematic of next generation sample for testing. 
Bare SS $300^{\circ} \mathrm{C} 200$ Torr

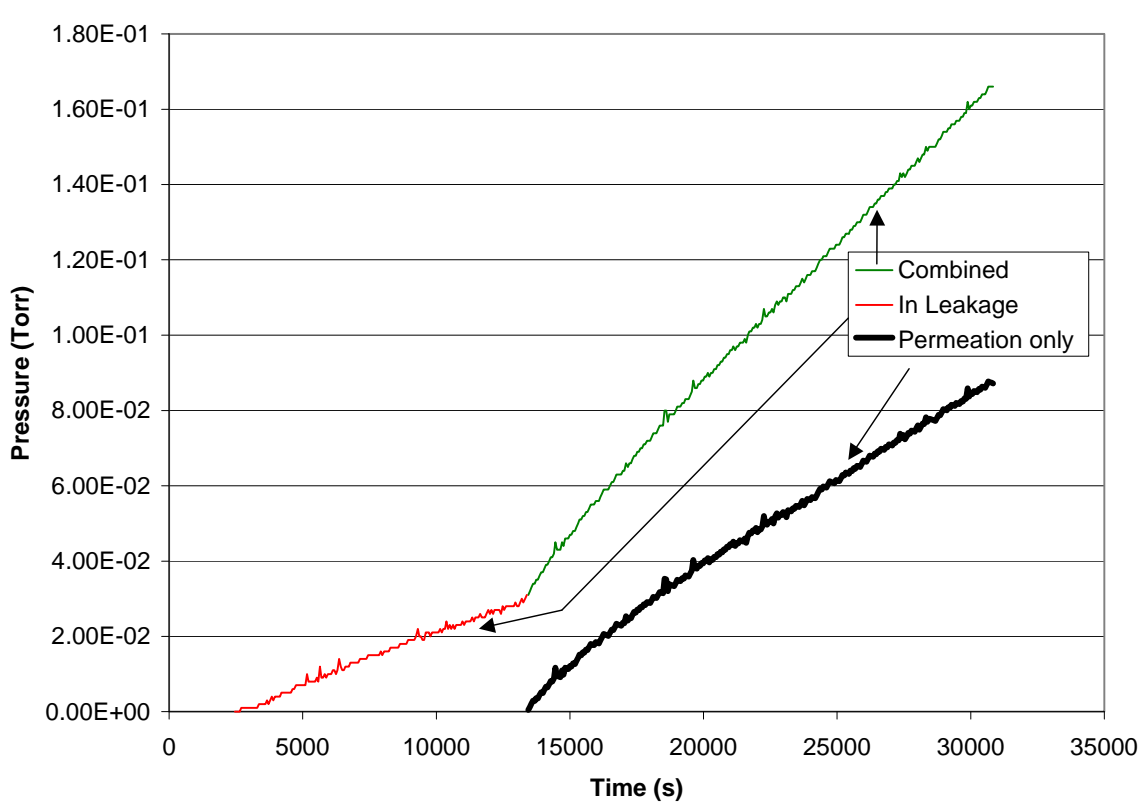

(a) the bare sample

HT NiCoCrAIY $200^{\circ} \mathrm{C}$ 200Torr

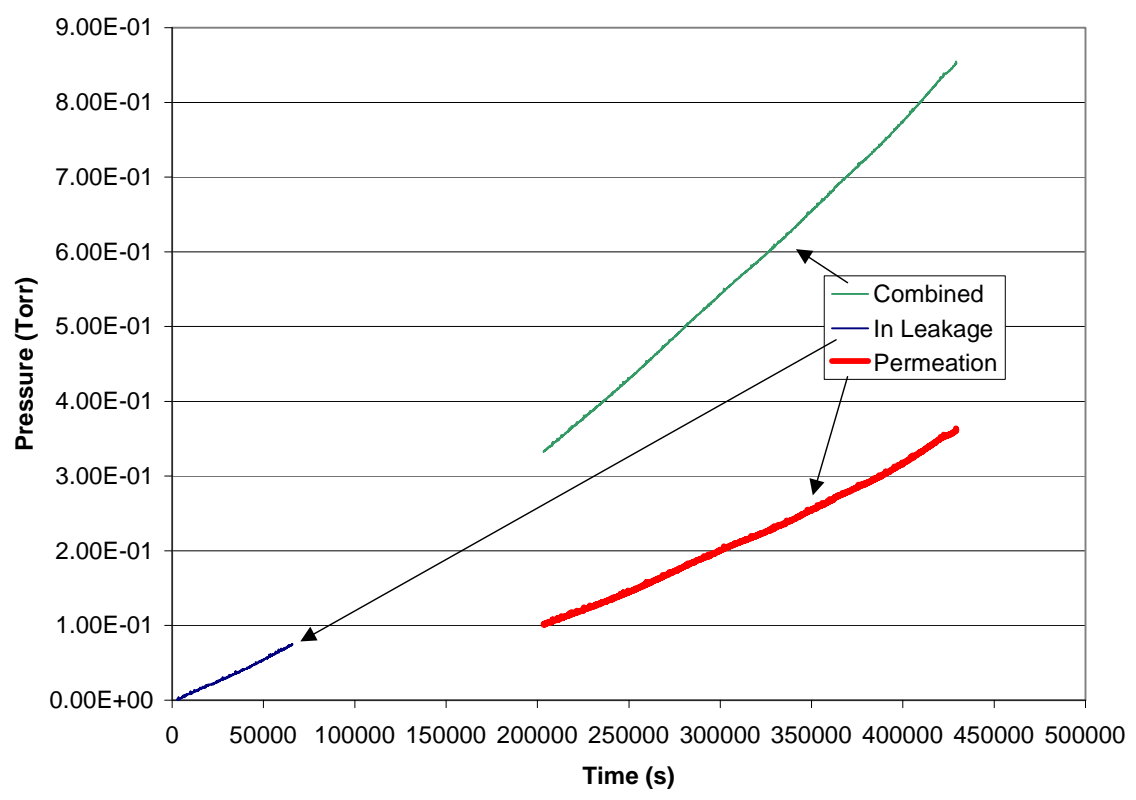

(b) the heat treated NiCoCrAlY coated sample

Fig. 13 Typical pressure-time data obtained from (a) the bare sample and (b) the heat treated NiCoCrAlY coated sample. 
WSRC-TR-2004-00040

\section{DISTRIBUTION}

R. L. Rabun

J. E. Marra

S. L. West

E. A. Clark

P. S. Korinko

N. C. Iyer

S. B. Wyrick

S. R. Howard

T. M. Adams
246-H

246-H

773-A

773-A

773-A

773-41A

773-A

232-H

773-41A 